\title{
DYNAMICS OF TWO COAXIAL CYLINDRICAL SHELLS CONTAINING VISCOUS FLUID
}

by

Tsyh-tyan Yeh and Shoei-sheng Chen

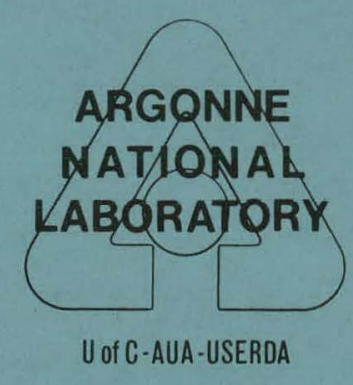

Base Technology

September 1976 


\section{DISCLAIMER}

This report was prepared as an account of work sponsored by an agency of the United States Government. Neither the United States Government nor any agency Thereof, nor any of their employees, makes any warranty, express or implied, or assumes any legal liability or responsibility for the accuracy, completeness, or usefulness of any information, apparatus, product, or process disclosed, or represents that its use would not infringe privately owned rights. Reference herein to any specific commercial product, process, or service by trade name, trademark, manufacturer, or otherwise does not necessarily constitute or imply its endorsement, recommendation, or favoring by the United States Government or any agency thereof. The views and opinions of authors expressed herein do not necessarily state or reflect those of the United States Government or any agency thereof. 


\section{DISCLAIMER}

Portions of this document may be illegible in electronic image products. Images are produced from the best available original document. 
The facilities of Argonne National Laboratory are owned by the United States Government. Under the terms of a contract (W-31-109-Eng-38) between the U. S. Energy Research and Development Administration, Argonne Universities Association and The University of Chicago, the University employs the staff and operates the Laboratory in accordance with policies and programs formulated, approved and reviewed by the Association.

\section{MEMBERS OF ARGONNE UNIVERSITIES ASSOCIATION}

The University of Arizona Carnegie-Mellon University Case Western Reserve University The University of Chicago

University of Cincinnati

Illinois Institute of Technology

University of Illinois

Indiana University

Iowa State University

The University of Iowa
Kansas State University The University of Kansas Loyola University Marquette University Michigan State University The University of Michigan University of Minnesota University of Missouri Northwestern University University of Notre Dame
The Ohio State University

Ohio University

The Pennsylvania State University

Purdue University

Saint Louis University

Southern Illinois University

The University of Texas at Austin

Washington University

Wayne State University

The University of Wisconsin

This report was prepared as an account of work sponsored by the United States Government. Neither the United States nor the United States Energy Research and Development Administration, nor any of their employees, nor any of their contractors, subcontractors, or their employees, makes any warranty, express or implied, or assumes any legal liability or responsibility for the accuracy, completeness or usefulness of any information, apparatus, product or process disclosed, or represents that its use would not infringe privately-owned rights. Mention of commercial products, their manufacturers, or their suppliers in this publication does not imply or connote approval or disapproval of the product by Argonne National Laboratory or the U. S. Energy Research and Development Administration. 
DYNAMICS OF TWO COAXIAL CYLINDRICAI SHELLS

CONTAINIING VISCOUS FLUID

by

Tsyh-tyan Yeh and Shoei-sheng. Chen

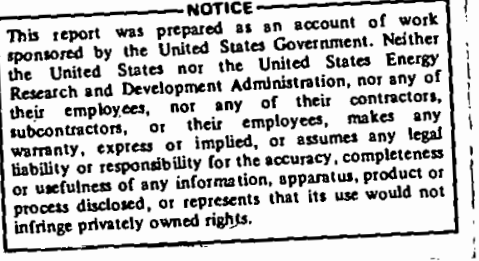

COMPONENTS TECHNOLOGY DIVISION

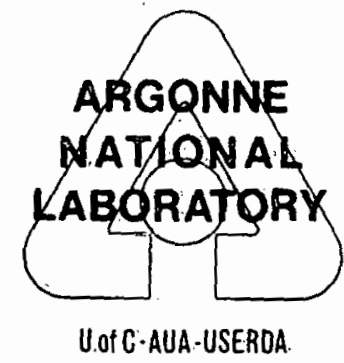

Base Technology

September 1976

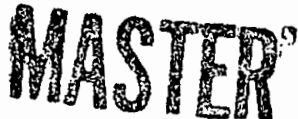




\section{ABSTRACT}

This study was motivated by the need to design the thermal shield in reactor internals and other system components to avoid detrimental.flowinduced vibrations. The system component is modeled as two coaxial shells separated by a viscous fluid. In the analysis, Flügge's shell equations. of motion and linearized Navier-Stokes equation for viscous fluid are employed. First, a traveling-wave type solution is taken for shells and fluid. Then, from the interface conditions between the shells and fluid, the solution for the fluid medium is expressed in terms of shell displacements. Finally, using the shell equations of motion gives the frequency equation, from which the natural frequency, mode shape, and modal damping ratio of coupled modes can be calculated. The analytical results show a fairly good qualitative agreement with the published experimental data. Some important conclusions are as follows: (1) In computing the natural frequencies and mode shapes of uncoupled modes and coupled modes, the fluid may be considered inviscid and incompressible. (2) There exists out-ofphase and in-phase modes. The lowest natural frequency is always associated with the out-of-phase mode. (3) The lowest natural frequency of coupled modes is lower than the uncoupled modes. (4) The fluid viscosity contributes significantly to damping, in particular, the modal damping of the out-ofphase modes is relatively large for small gaps. (5) If the fluid gap is sma11, or the fluid viscosity is relatively high, the simulation of the vibration Reynolds number should be included to ensure that modal damping of the model is properly accounted for. With the presented analysis and results, the frequency and damping characteristics can be analyzed and design parameters can be related to frequency and damping. 
TABLE OF CONTENTS

Page

ABSTRACT . . . . . . . . ................ . 1

LIST OF FIGURES. . . . . . . . . . . . . . . . . . . . . iii

LIST OF TABLES . . . . . . . . . . . . . . . . . . . iv

NOMENCLATURE . . . . . . . . . . . . . . . . . . . . v v v

I. INTRODUCTION . . . . .................. . . . 1

II. GOVERNING EQUATIONS OF MOTION. . . . . . ....... 3

III. FLUID STRESS COEFFICIENT MATRIX. . . . . . . ........ . 7

A. Analysis . . . . . . . . . . . . . . . . 7

B. Numerical Results. . . . . . . . . . . . . 14

IV. THE FREQUENCY EQUATION . . . . . . . . . . . . . . 23

A. Analysis .................... 23

B. Numerical Example. . . . . . . . . . . . 25

V. COMPARISON OF ANALYTICAL AND EXPERIMENTAL RESULTS. . . . . . 33

VI. CONCLUDING REMARKS . . . . . . . . . . . . . . 38

ACKNOWLEDGMENTS. . . . . . . . . . . . . . . . . . . . . . . 40

REFERENCES .......................... . . . 41

APPENDIX: ' COMPUTER PROGRAM (HDSC) . . . . . . . . . . . . . 42 


\section{LIST OF FIGÜRS}

No.

Title

Schematic of Two Concentric Cylindrical Shells

Containing a Viscous Fluid

Stress Coefficient $\alpha_{33}$ as a Function of Reynolds

Number $\operatorname{Re}_{1}$ for $\alpha_{1}=\pi, \mathrm{r}_{2} / \mathrm{r}_{1}=1.1$, and $\mathrm{Mo}_{1}=0.0$

Real Parts of.Stress Coefficients as Functions of

Radius Ratio $r_{2} / r_{1}$ for $\alpha_{1}=\pi$ and $\mathrm{Mo}_{1}=0.0$.

$\longrightarrow: \operatorname{Re}\left\{\alpha_{66}\right\} ;----: \operatorname{Re}\left\{\dot{\alpha}_{33}\right\}$.

4

Imaginary Parts of Stress Coefficients as Functions

of $r_{2} / r_{1}$ for $\alpha_{1}=\pi$ and $M_{.1}=0.0$ : $\operatorname{Im}\left\{-a_{66}\right\}$;

$---1: \operatorname{Im}\left\{-\alpha_{33}\right\}$.

20

5

Stress Coefficient $\alpha_{36}$ os a Function of $\mathrm{r}_{2} / \mathrm{r}_{1}$ for

$\alpha_{1}=\pi$ and $\mathrm{Mo}_{1}=0.0$. $\mathrm{n}=1 ;----: \mathrm{n}=4.22$

6

Natural Frequencies of Sheil Systems

Modal Damping Ratio $\zeta$ of a Fluid/Shell System

Modal Shape of a Coupled Fluid/Shell System 


\section{LIST OF TABLES}

No.

Title

1

Dynamic Stress Coefficient Matrix $\alpha_{p q}$ for $\alpha_{1}=\pi$,

$\mathrm{r}_{2} / \mathrm{r}_{1}=1.2$ and $\mathrm{Mo}_{1}=0.0$

2

Natural Frequencies and Related Modai Damping Ratio

of a Shell System

Modal Shapes of Out-of-Phase and In-Phase Modes of

a Coupled Fluid/Shell System $\left(\bar{w}_{1}=1.0\right)$

4. Comparison of Experimental and Analytical Frequency

Ratio 


\section{NOMENCLATURE}

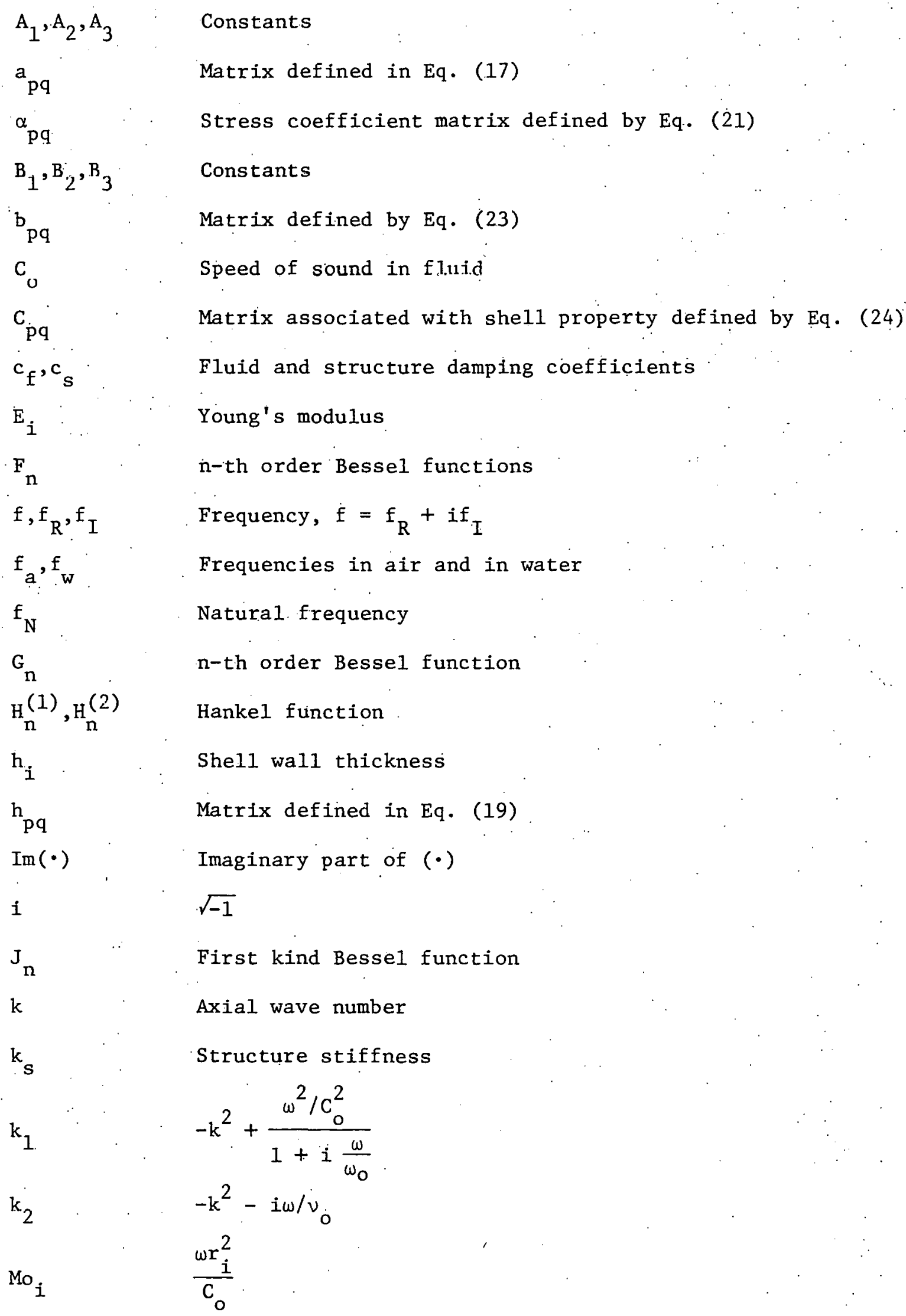


NOMENCLATURE (Contd.)

$\mathrm{m}_{\mathrm{a}}, \mathrm{m}_{\mathrm{s}}$

n

$\mathrm{p}, \mathrm{p}_{\mathrm{o}}$

$P_{\theta i}, P_{z i}, P_{r i}$

$R_{i}$

$\operatorname{Re}(\cdot)$

$\mathrm{Re}_{i}$

$\mathbf{r}$

$r_{i}$

t

$\tau_{r r}, \tau_{r \theta}, \tau_{r z}$

$u_{i}, \bar{u}_{i}$

$\overrightarrow{\mathrm{V}}$

$v_{i}, \bar{v}_{i}$

$w_{i}, \bar{w}_{i}$

$\omega$

$\omega_{0}$

$\mathrm{Y}_{\mathrm{n}}$

z

$\alpha_{i}$

$\delta_{i}$

$\cdot \theta$

$\mu_{i}$

$v_{i}$

$v_{0}, v_{0}^{\prime}$

$\rho_{i}$

$\rho_{0}, \rho$
Added and shell mass per unit shell surface area

Circumferential wave number

Total pressure and reference pressure

Shell surface loading stresses due to fluid

Mean radius of she11.

Real part of $(\cdot)$

$\frac{w r_{i}^{2}}{v_{0}}$, Reynolds number

Radial coordinat.e

Radius of interface

Time

Fluid stresses

Axial displacement of shell

Fluid velocity, $\left(\mathrm{V}_{\mathrm{r}}, \mathrm{V}_{\theta}, \mathrm{V}_{\mathrm{z}}\right)$

Circumferential displacement of shell

Radial displacement of shell

Circular frequency, $2 \pi f$

$c_{0}^{2} /\left(\frac{4}{3} v_{0}+v_{0}^{\prime}\right)$

Second kind Bessel function

Axial coordinate

$\mathrm{kr}_{\mathbf{i}}$

$h_{i} / R_{i}$

Angular coordinate

$\frac{\rho_{o} r_{i}}{\rho_{i} h_{i}}$

Poisson's ratio

Kinematic and secondary viscosity of the fluid

Shell density

Fluid density 
vii

$\Omega_{i}$

$$
\vec{\psi}
$$

$\phi, \bar{\phi}$

$\zeta$

$\zeta_{\mathrm{s}}$

$\zeta_{t}$

$\delta$

$$
\begin{aligned}
& \text { NOMENCLATURE (Contd.) } \\
& \mathrm{R}_{i} \omega\left[\frac{\rho_{i}\left(1-v_{i}^{2}\right)}{E_{i}}\right]^{1 / 2} \\
& \left(\psi_{z}, \psi_{\theta}, \psi_{r}\right) \text {, vector potential of the velocity field } \\
& \text { Scalar potential of the velocity field } \\
& \text { Modal damping ratio associated with fluid viscosity } \\
& \text { Structure damping ratio in vacuo } \\
& \zeta_{s}+\tau \text {, total damping ratio } \\
& \delta_{\mathrm{pq}}=1 \text { if } \mathrm{p}=\mathrm{q} \text {, otherwise } \delta_{\mathrm{pq}}=0
\end{aligned}
$$




\section{INTRODUCTION}

In this report, the dynamics of a system of two concentric cylindrical shells coupled by a viscous fluid is studied analytically. The objective is to investigate the effect of fluid viscosity on fluid structure interactions:

This study was motivated by the need to design reactor system components to avoid detrimental flow-induced vibrations. Several reactor system components consist of nominally circular cylindrical shells coupled to other shells through a fluid. Examples include shrouds and thermal liners. Those components are subject to various excitation sources including fluid flow and structural borne disturbance. To design a component such that over the design life its performance will not be affected by vibrations, one must understand the system characteristics.

Vibrations of two coaxial shells separated by a fluid have been studied extensively [1-4]. However, all those investigations omit the effect of fluid viscosity. Although for many practical applications, the viscosity is small and the fluid may be considered inviscid as a first approximation, near the interface of the structure and fluid there exists a thin layer of rotational flow. This flow regime in which the viscous effect is significant is of great concern to the dynamic response of coupled shell systems. In particular, when the annular gap is small, the fluid viscous effect becomes more pronounced.

In this study, Flügge's shell equations of motion and the linearized Navier-Stokes equation for fluid are employed. First, a traveling-wave type solution is taken for shells and fluid. Then, from the interface conditions between the shells and fluid, the solution for fluid medium 
is expressed in terms of shell displacements. Finally, using the shell equations of motion gives the frequency equation from which the natural frequency, mode shape, and the modal damping ratio can be calculated. The analytical results are also compared with an experimental investigation for two concentric shells coupled by water. 
II. GOVERIIING EQUATIONS OF MOTION

Consider two concentric circular cylindrical shells separated by a viscous fluid annulus as shown in Fig. 1. The motion of the shells is described by the following Flügge's shell equation [5]:

$$
\begin{aligned}
& {\left[\frac{\partial^{2}}{\partial z^{2}}+\left(\frac{1-v_{i}}{2 R_{i}^{2}}\right)\left(1+\frac{h_{i}^{2}}{1.2 R_{i}^{2}}\right) \frac{\partial^{2}}{\partial \theta^{2}}\right] u_{i}+\frac{1+v_{1}}{2 R_{i}} \frac{\partial^{2} v_{1}}{\partial z \partial \theta}} \\
& +\left[\frac{\nu_{i}}{R_{i}} \frac{\partial}{\partial z}-\frac{h_{i}^{2}}{12 R_{i}} \frac{\partial^{3}}{\partial z^{3}}+\frac{\left(1-\nu_{i}\right) h_{i}^{2}}{24 R_{i}^{3}} \frac{\partial^{3}}{\partial z \partial \theta^{2}}\right] w_{i} \\
& =\frac{\rho_{i}\left(1-v_{i}^{2}\right)}{E_{i}} \frac{\partial^{2} u_{i}}{\partial t^{2}}-\frac{1-v_{i}}{E_{i} h_{i}} P_{z i} \\
& \frac{1+v_{i}}{2 R_{i}} \frac{\partial^{2} u_{i}}{\partial z \partial \theta}+\left[\frac{1}{R_{i}^{2}} \frac{\partial^{2}}{\partial \theta^{2}}+\frac{1-v_{i}}{2}\left(1+\frac{h_{i}{ }^{2}}{4 R_{i}^{2}}\right) \frac{\partial^{2}}{\partial z^{2}}\right] \cdot v_{i} \\
& +\left[\frac{1}{R_{i}^{2}} \frac{\partial}{\partial \theta}-\frac{\left(3-v_{i}\right) h_{i}^{2}}{24 R_{i}^{2}} \frac{\partial^{3}}{\partial \theta \partial z^{2}}\right] w_{i}=\frac{\rho_{i}\left(i-v_{i}\right)^{2}}{E_{i}} \frac{\partial_{i}^{2} v_{i}}{\partial t^{2}} \\
& -\frac{1-v_{i}^{2}}{E_{i} h_{i}} \quad P \cdot \theta_{i} \\
& {\left[-\frac{h_{i}^{2}}{12 \frac{R_{i}}{\partial z^{3}}}+\frac{\partial^{3}}{R_{i}} \frac{\partial}{\partial z}+\frac{\left(1-\nu_{i}\right) h_{i}^{2}}{24 R_{i}^{3}} \frac{\partial^{3}}{\partial z \partial \theta^{2}}\right] u_{i}} \\
& +\left[-\frac{\left(3-v_{i}\right) h_{i}^{2}}{24 R_{i}^{2}} \frac{\partial^{3}}{\partial \theta \partial z^{2}}+\frac{1}{R_{i}^{2}} \frac{\partial}{\partial \theta}\right] v_{i}
\end{aligned}
$$




$$
\begin{aligned}
+\left[\frac{1}{R_{i}^{2}}\right. & \left.+\frac{h_{i}^{2}}{12 R_{i}^{4}}+\frac{h_{i}^{2}}{12} \frac{\partial^{4}}{\partial z^{4}}+\frac{h_{i}^{2}}{6 R_{i}^{2}} \frac{\partial^{4}}{\partial z^{2} \partial \theta^{2}}+\frac{h_{i}^{2}}{12 R_{i}^{4}} \frac{\partial^{4}}{\partial \theta^{4}}+\frac{h_{i}^{2}}{6 R_{i}^{4}} \frac{\partial^{2}}{\partial \theta^{2}}\right] w_{i} \\
& =-\frac{\rho_{i}\left(1-\nu_{i}^{2}\right)}{E_{i}} \frac{\partial^{2} w_{i}}{\partial t^{2}}+\frac{1-\nu_{i}^{2}}{E_{i} h_{i}} P_{r i}
\end{aligned}
$$

where the index $i$ denotes the variables associated with the inner shell $(i=1)$ and outer shell $(i=2) ; u_{i}, v_{i}, w_{i .}$ are the displacement components of the shell middle surfaces; $z, \theta$, and $r$ are cylindrical coordinates; $\mathrm{P}_{z i}, \mathrm{P}_{\theta i}$, and $\mathrm{P}_{\mathrm{ri}}$ are the surface loading components per untt ared, and $t$ is the time. The physical characteristics of shells are defined by the mean radius $R_{i}$, wall thickness $h_{i}$, mass density $\rho_{i}$, Young's modulus $E_{i}$ and Poisson's ratio $\nu_{i}$.

For a non-steady, smal1-amplitude oscillatory motion, the equations of motion for the contained viscous fluid can be expressed as follows [6]:

$$
\begin{aligned}
& \frac{\partial \rho}{\partial t}+\rho_{0} \nabla \cdot \vec{v}=0 \\
& \frac{\partial \vec{v}}{\partial t}=-\frac{1}{\rho_{0}} \nabla p+\left(\frac{4}{3} \nu_{0}+\nu_{0}^{\prime}\right) \nabla(\nabla \cdot \vec{v})-\nu_{0} \nabla \times \nabla \times \vec{\nabla} \\
& \frac{\partial p}{\partial \rho}=c_{0}^{2},
\end{aligned}
$$

where $\rho_{0}$ and $\rho$ are the mean and instantaneous fluid mass densities, $\nu_{0}$ and $v_{o}^{\prime}$ are the kinematic and second viscosities of the fluid, $C_{0}$ is the speed of sound in fluid, $p$ is fluid pressure and $\vec{V}$ is fluid velocity vector. 


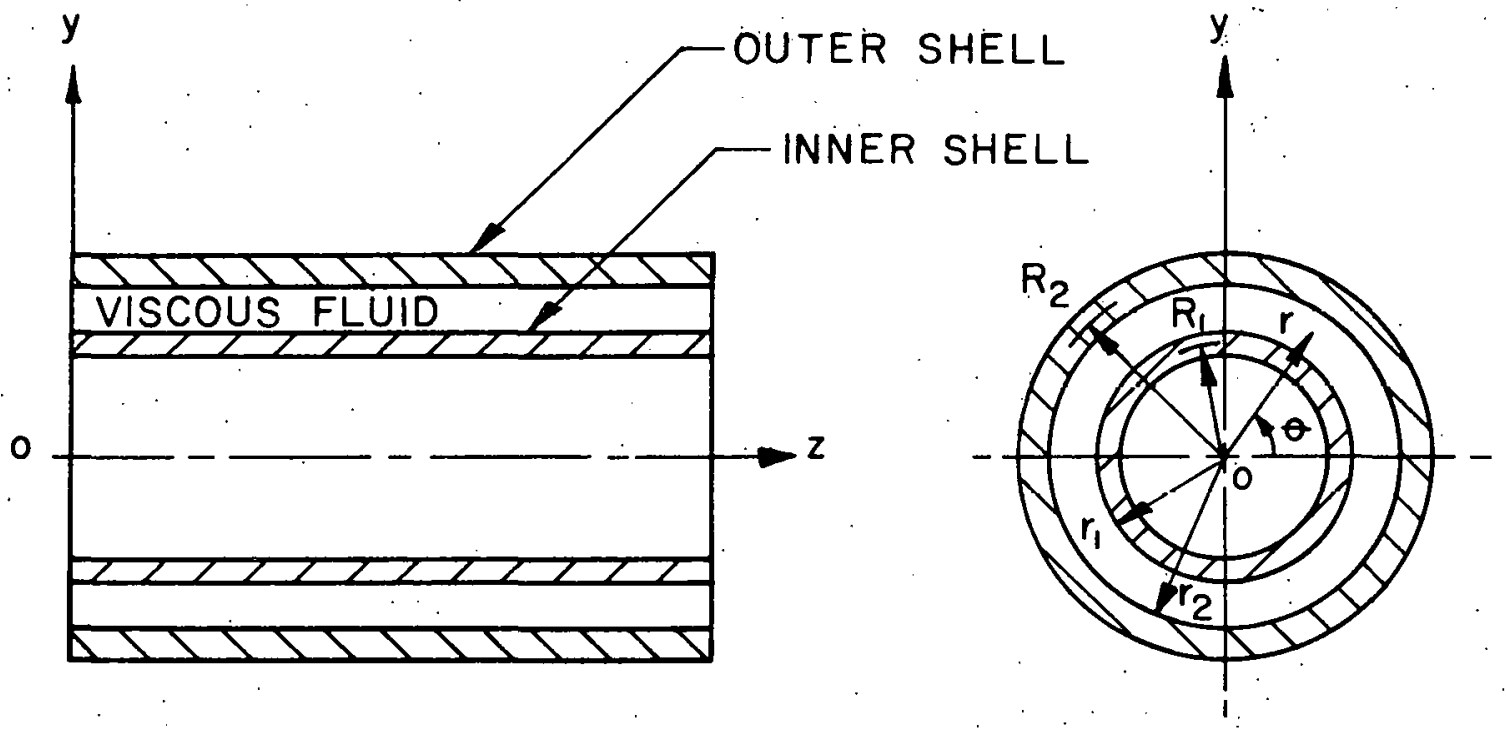

Fig. 1. Schematic of two concentric cylindrical shells containing a viscous fluid. 
At the interfaces between the shells and fluid, the following conditions must be satisfied:

$$
v v_{z=r_{i}}=\frac{\partial u_{i}}{\partial t} ;\left.\quad v_{\theta}\right|_{r=r_{i}}=\frac{\partial v_{i}}{\partial t} ; \text { and }\left.v_{r}\right|_{r=r_{i}}=\frac{\partial w_{i}}{\partial t} \text { with } i=1 \text { and } 2 \text {. }
$$

The surface loading acting on the shells is given by

$$
\mathrm{P}_{\ell 1}=\left.{ }^{\tau} \mathrm{r} \ell\right|_{\mathrm{r}=\mathrm{r}_{1}} \text { and } \mathrm{P}_{\ell 2}=-\left.\tau_{\mathrm{r} \ell}\right|_{\mathrm{r}=\mathrm{r}_{2}} \text { with } \ell=z, \theta \text {, and } \mathrm{r}
$$

where $r_{1}=R_{1}+h_{1} / 2$ and $r_{2}=R_{2}-h_{2} / 2$ are the interface radii, and $\tau_{r r}, \tau_{r \theta}$, and $\tau_{r z}$ are the fluid stresses:

$$
\begin{aligned}
& \tau_{r r}=-p+2 \mu \frac{\partial V_{r}}{\partial r}, \\
& \tau_{r \theta}=\mu\left[r \frac{\partial}{\partial r}\left(\frac{V_{\theta}}{r}+\frac{1}{r} \frac{\partial V_{r}}{\partial \theta}\right)\right], \\
& \tau_{r z}=\mu\left(\frac{\partial V_{r}}{\partial z}+\frac{\partial V_{z}}{\partial r}\right) .
\end{aligned}
$$

Here $\mu$ is fluid viscosity.

Equations (1) through (5), are the complete mathematical statement of the coupled viscous fiuid/shell system. 
III. FLUID STRESS COEFFICIENT MATRIX

\section{A. Analysis \\ Letting}

$$
\vec{V}=\nabla \times \vec{\psi}+\nabla \phi
$$

and inserting it into equations (2) yields

$$
\frac{\partial \nabla \phi}{\partial t}=\frac{1}{\rho_{0}} \cdot \nabla p+\left(\frac{4 v_{0}}{3}+\nu_{o}^{\prime}\right) \nabla \nabla^{2} \psi,
$$

and

$$
\frac{\partial \nabla \times \vec{\psi}}{\partial t}=-v_{0} \nabla \times \nabla \times \nabla \times \vec{\psi}
$$

Integration of the first equation of Eq. (7) gives

$$
p=p_{0}-\rho_{0} \frac{\partial \phi}{\partial t}+\rho_{0}\left(\frac{4 \nu_{0}}{3}+\nu_{0}^{\prime}\right) \nabla^{2} \phi
$$

From equations (2) and (8), we have

$$
\left[\left(1+\frac{1}{\omega_{0}} \frac{\partial}{\partial t}\right) \nabla^{2}-\frac{1}{c_{0}^{2}} \frac{\partial^{2}}{\partial t^{2}}\right] \phi=0,
$$

where

$$
\omega_{0}=c_{0}^{2} /\left(\frac{4}{3} v_{0}+v_{0}^{\prime}\right)
$$

Equation ( 8 ) shows that the fluid pressure is not affected by the waves produced from the vector potential, $\vec{\psi}$, which is associated with the fluid viscosity. Since the trival solution $(\nabla \times \vec{\psi}=0)$ is to be excluded, equation ( 7 ) can further be reduced to

$$
\left(\frac{\partial}{\partial t}-\nu_{0} \nabla^{2}\right) \dot{\psi}=0
$$

or in cylindrical coordinates, 


$$
\begin{aligned}
& \left(\frac{1}{\nu_{0}} \frac{\partial}{\partial t}-\nabla^{2}\right) \psi_{z}=0, \\
& \left(-\frac{1}{v_{0}} \frac{\partial}{\partial t}-\nabla^{2}\right) \psi_{\theta}+\frac{\psi_{\theta}}{r^{2}}-\frac{2}{r^{2}} \frac{\partial \psi_{r}}{\partial \theta}=0,
\end{aligned}
$$

and

$$
\left(\frac{1}{\nu_{0}} \frac{\partial}{\partial t}:-\dot{\nabla}^{2}\right) \cdot \psi_{r}+\frac{\psi_{1}}{r^{2}}+\frac{2}{r^{2}} \cdot \frac{\partial \psi_{\theta}}{\partial \theta}=0
$$

Solutions of the following form are assumed for the shells:

$$
\begin{aligned}
& u_{i}=i \bar{u}_{i} \cos (n \theta) \exp [i(\omega t-k z)], \\
& v_{i}=\bar{v}_{i} \sin (n \theta) \exp [i(\omega t-k z)], \\
& w_{i}=\bar{w}_{i} \cos (n \theta) \exp [i(\omega t-k z)] ;
\end{aligned}
$$

where $i=\sqrt{-1}, n$ is the circumferential wave number, $\omega$ is the circular frequency, $k$ is the axial wave number, and $\bar{u}_{i}, \bar{v}_{i}$ and $\bar{w}_{i}$ are arbitrary constants to be determined.

Similarly, the fluid velocity potential may be assumed as follows:

$$
\begin{aligned}
& \phi=\bar{\phi}(r) \cos n \theta \exp [i(\omega t-k z)], \\
& \psi_{z}=\bar{\psi}_{z}(r) \sin n \theta \exp [i(\omega t-k z)], \\
& \psi_{\theta}=i \bar{\psi}_{\theta}(r) \cos n \theta \exp [i(\omega t-k z)], \\
& \psi_{r}=i \bar{\psi}_{r}(r) \sin n \theta \exp [i(\omega t-k z)] .
\end{aligned}
$$

Substituting Eqs. (13) into (9) and (11) gives the following forms of Bessel's equations: 


$$
\begin{aligned}
& {\left[\frac{1}{r} \cdot \frac{\partial}{\partial r}\left(r \frac{\partial}{\partial r}\right)+\left(k_{1}^{2}-\frac{n^{2}}{r^{2}}\right)\right] \bar{\phi}=0,} \\
& {\left[\frac{1}{r} \cdot \frac{\partial}{\partial r}\left(r \frac{\partial}{\partial r}\right)+\left(k_{2}^{2}-\frac{n^{2}}{r^{2}}\right)\right] \bar{\psi}_{z}=0,} \\
& \frac{1}{r} \frac{\partial}{\partial r}\left(r \frac{\partial}{\partial r} \bar{\psi}_{\theta}\right)+\left(k_{2}^{2}-\frac{n^{2}+1}{r^{2}}\right) \bar{\psi}_{\theta}+\frac{2 n}{r^{2}} \bar{\psi}_{r}=0, \\
& \frac{1}{r} \frac{\partial}{\partial r}\left(r \frac{\partial}{\partial r} \bar{\psi}_{r}\right)+\left(k_{2}{ }^{2}-\frac{n^{2}+1}{r^{2}}\right) \bar{\psi}_{r}+\frac{2 n}{r^{2}} \bar{\psi}_{\theta}=0
\end{aligned}
$$

where

$$
\begin{aligned}
& k_{1}=\left(-k^{2}+\frac{\omega^{2} / c_{0}^{2}}{1+i \frac{\omega}{\omega_{0}}}\right)^{1 / 2}, \\
& k_{2}=\left(-k^{2}-i \frac{\omega}{v_{0}}\right)^{1 / 2} .
\end{aligned}
$$

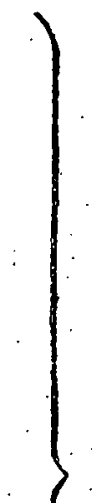

The general solutions of equations (14) are

$$
\left.\begin{array}{l}
\bar{\phi}(r)=i \omega\left[A_{1} F_{n}\left(k_{1} r\right)+B_{1} G_{n}\left(k_{1} r\right)\right] \\
\bar{\psi}_{z}(r)=i \omega\left[A_{2} F_{n}\left(k_{2} r\right)+B_{2} G_{n}\left(k_{2} r\right)\right] \\
\bar{\psi}_{1}(r)=\frac{1}{2}\left(\bar{\psi}_{r}-\bar{\psi}_{\theta}\right)=i \omega\left[A_{3} F_{n+1}\left(k_{2} r\right)+B_{3} G_{n+1}\left(k_{2} r\right)\right] \\
\bar{\psi}_{2}(r)=\frac{1}{2}\left(\bar{\psi}_{r}+\bar{\psi}_{\theta}\right)=i \omega\left[A_{4} F_{n-1}\left(k_{2} r\right)+B_{4} G_{n-1}\left(k_{2} r\right)\right],
\end{array}\right\}
$$

where $F_{n}$ and $G_{n}$ are the $n$-th order Bessel functions. They can be either the first and second kind Bessel functions, $J_{n}$ and $Y_{n}$, or the Hankel functions $H_{n}{ }^{(1)}$ and $H_{n}{ }^{(2)}$. The selection of the functions mainly depends on the computational consideration. 
It may be shown that any one of the three potentials, $\bar{\psi}_{z}, \bar{\psi}_{1}$, and $\bar{\psi}_{2}$, can be set equal to zero without any loss of generality of the solution. Thus, let $\bar{\psi}_{2}=0$, and the general solution becomes

$$
\begin{aligned}
& \dot{\bar{\phi}}(r)=i \text { (1) }\left[A_{1} F_{n}\left(k_{1} r\right)+B_{1} G_{n}\left(k_{1} r\right)\right], \\
& \bar{\psi}_{z}(r)=i \omega\left[A_{2} F_{n}\left(k_{2} r\right)+B_{2} G_{n}\left(k_{2} r\right)\right], \\
& \bar{\psi}_{r}(i)=-\bar{\psi}_{\theta}(r)=i\left(n\left[\Lambda_{3} F_{n+1}\left(k_{2} r\right)+R_{3} F_{n+1}\left(k_{2} r\right)\right] .\right.
\end{aligned}
$$

Substituting equations (12), (13), and (16) into the interface conditions, Eq. (3), gives six linear, algebraic equations:

$$
\left\{a_{p q}\right\}\left\{\begin{array}{c}
A_{1} \\
B_{1} \\
A_{2} \\
B_{2} \\
A_{3} \\
B_{3}
\end{array}\right\}=\left\{\begin{array}{c}
r_{1} \bar{u}_{1} \\
r_{1} \cdot \bar{v}_{1} \\
r_{1} \bar{w}_{1} \\
r_{2} \bar{u}_{2} \\
r_{2} \bar{v}_{2} \\
r_{2} \bar{w}_{2}
\end{array}\right\}, p, q=1 \text { to } 6 \text {, }
$$

where

$$
\begin{aligned}
& a_{11}=-\alpha_{1} F_{n}\left(\gamma_{1}\right), \quad a_{12}=-\alpha_{1} G_{n}\left(\gamma_{1}\right), \quad a_{13}=a_{14}=0, \\
& a_{15}=-\beta_{1} F_{n}\left(\beta_{1}\right), \quad a_{16}=-\beta_{1} G_{n}\left(\beta_{1}\right), \quad a_{21}=-n F_{n}\left(\gamma_{1}\right), \\
& a_{22}=-n G_{n}\left(\gamma_{1}\right), \quad a_{23}=\beta_{1} F_{n+1}\left(\beta_{1}\right)-n F_{n}\left(\beta_{1}\right) \text {, } \\
& a_{24}=\dot{\beta}_{1} G_{n+1}\left(\beta_{1}\right)-n G_{n}\left(\beta_{1}\right), \quad a_{25}=a_{35}=\alpha_{1} F_{n+1}\left(\beta_{1}\right), \\
& a_{26}=a_{36}=\alpha_{1} G_{n+1}\left(\beta_{1}\right) \quad: \quad a_{31}=n F_{n}\left(\gamma_{1}\right)-\gamma_{1} F_{n+1}\left(\gamma_{1}\right), \\
& a_{32}=n G_{n}\left(\gamma_{1}\right)-\gamma_{1} G_{n+1}\left(\gamma_{1}\right) \quad a_{33}=n F_{n}\left(\beta_{1}\right) \\
& a_{34}=n G_{n}\left(\beta_{1}\right) \quad \text { and } \quad \alpha_{i}=k r_{i}, \cdot \beta_{i}=k_{2} r_{i}, \quad \gamma_{i}=k_{1} r_{i}
\end{aligned}
$$


The expression of $a_{p q}$ for $p=4,5 ; 6$ is similar to those for $p=1,2,3$ and can be obtained by replacing $\alpha_{1}, \beta_{1}$, and $\gamma_{1}$ by $\alpha_{2}, \beta_{2}$, and $\gamma_{2}$. Now we are in the position to calculate the loading stresses on the shell surfaces. Equation (8) is used to calculate the fluid pressure

$$
p:=p_{0}-\frac{i \rho_{0} \omega \phi}{1+i \frac{\omega}{\omega_{0}}}
$$

Here only the dynamic quantity is of interest and thus the reference pressure $\mathrm{p}_{\mathrm{o}}$ will not be considered. The equation (5) is used to obtain the fluid stresses. Define the new variables $\overline{\mathrm{P}}_{z i}, \overline{\mathrm{P}}_{\theta i}$, and $\overline{\mathrm{P}}_{\mathrm{r}}$ as follows:

$$
\begin{aligned}
& P_{z i}=i \rho_{0} \omega^{2} \bar{P}_{z i} \cos (n \theta) \exp [i(\omega t-k z)] \\
& P_{\theta i}=\rho_{0} \omega^{2} \bar{P}_{\theta i} \sin (n \theta) \exp [i(\omega t-k z)]
\end{aligned}
$$

and .

$$
P_{r i}=\rho_{0} \omega^{2} \bar{P}_{r i} \cos (n \theta) \exp \left[i\left(\omega t-\dot{k}_{z}\right)\right]
$$

Substituting equation (18) into (4) and using (13) and (16) yield another six linear, algebraic equations:

$$
\left\{h_{p q}\right\}\left\{\begin{array}{l}
A_{1} \\
B_{1} \\
A_{2} \\
B_{2} \\
A_{3} \\
B_{3} \\
A_{3}
\end{array}=\left\{\begin{array}{c}
\bar{P}_{z 1} \\
\bar{p}_{\theta 1} \\
\bar{P}_{z 2} \\
\bar{P}_{\theta 2} \\
\bar{P}_{r 2}
\end{array}\right\} ; p, q=1 \text { to } 6\right.
$$

where

$$
\begin{aligned}
& h_{11}=2 s_{1} \sigma_{1}\left[F_{n+1}\left(\gamma_{1}\right)-\frac{n}{\gamma_{1}} F_{n}\left(\gamma_{1}\right)\right], \\
& h_{12}=2 s_{1} \sigma_{1}\left[G_{n+1}\left(\gamma_{1}\right)-\frac{n}{\gamma_{1}} G_{n}\left(\gamma_{1}\right)\right],
\end{aligned}
$$


12

$$
\begin{aligned}
& h_{13}=-\frac{S_{2} \sigma_{2} n}{\beta_{1}} F_{n}\left(\beta_{1}\right) \quad, \quad h_{14}=-\frac{S_{2} \sigma_{2} n}{\beta_{1}} G_{n}\left(\beta_{1}\right), \\
& h_{15}=-S_{2}\left\{\left(\sigma_{2}^{2}-1\right) F_{n+1}\left(\beta_{1}\right)+\frac{n}{\beta_{1}} F_{n}\left(\beta_{1}\right)\right\} \text {, } \\
& h_{16}=-S_{2}\left\{\left(\sigma_{2}^{2}-1\right) G_{n+1}\left(\beta_{1}\right)+\frac{n}{\beta_{1}} G_{n}\left(\beta_{1}\right)\right\} \text {, } \\
& h_{21}=\frac{2 S_{1} n}{\gamma_{1}}\left[F_{n+1}\left(\gamma_{1}\right)-\frac{n-1}{\gamma_{1}} F_{n}\left(r_{1}\right)\right] \text {, } \\
& h_{22}=\frac{2 S_{1} n}{\gamma_{2}}\left[G_{n+1}\left(\gamma_{1}\right)-\frac{n-1}{\gamma_{1}} G_{n}\left(r_{1}\right)\right] \text {, } \\
& h_{23}=-S_{2}\left\{\left[\frac{2 n(n-1)}{\beta_{1}^{2}}-1\right] F_{n}\left(\beta_{1}\right)+\frac{2}{\beta_{1}} F_{n+1}\left(\beta_{1}\right)\right\} \text {, } \\
& h_{24}=-S_{2}\left\{\left[\frac{2 n(n-1)}{\beta_{1}^{2}}-1\right] G_{n}\left(\beta_{1}\right)+\frac{2}{\beta_{1}} G_{n+1}\left(\beta_{1}\right)\right\} \text {, } \\
& h_{25}=s_{2} \sigma_{2}\left[F_{n}\left(\beta_{1}\right)-\frac{2(n+1)}{\beta_{1}} F_{n+1}\left(\beta_{1}\right)\right] \text {, } \\
& h_{26}=s_{2} \sigma_{2}\left[G_{n}\left(\beta_{1}\right)-\frac{2(n+1)}{\beta_{1}} G_{n+1}\left(\beta_{1}\right)\right] \text {, } \\
& \begin{array}{l}
h_{31}=\left[\frac{2 s_{1} n(n+1)}{\gamma_{1}^{2}}-\left(2 s_{1}+\frac{1}{1+i \frac{\omega}{\omega_{0}}}\right)\right] F_{n}\left(\gamma_{1}\right)+\frac{2 s_{1}}{\gamma_{1}} F_{n+1}\left(\gamma_{1}\right), \\
h_{32}=\left[\frac{2 s_{1} n(n+1)}{\gamma_{1}^{2}}-\left(2 s_{1}+\frac{1}{1+i \frac{\omega}{\omega_{0}}}\right] G_{n}\left(\gamma_{1}\right)+\frac{2 s_{1}}{\gamma_{1}} G_{n+1}\left(\gamma_{1}\right),\right.
\end{array} \\
& h_{33}=\frac{2 S_{2} n}{\beta_{1}}\left[\frac{n-1}{\beta_{1}} F_{n}\left(\beta_{1}\right)-F_{n+1}\left(\beta_{1}\right)\right] ; \\
& h_{34}=\frac{2 S_{2}{ }^{i 1}}{\beta_{1}}\left[\frac{n-1}{\beta_{1}} G_{n}\left(\beta_{1}\right)-G_{n+1}\left(\beta_{1}\right)\right] \text {, } \\
& h_{35}=2 S_{2} \sigma_{2}\left[F_{n}\left(\beta_{1}\right)-\frac{n+1}{\beta_{1}} F_{n+1}\left(\beta_{1}\right)\right] \text {, } \\
& h_{36}=2 S_{2} \sigma_{2}\left[G_{n}\left(\beta_{1}\right)-\frac{n+1}{\beta_{1}} G_{n+1}\left(\beta_{1}\right)\right] \text {, } \\
& \text { and } S_{1}=i \frac{\gamma_{1}^{2}}{\operatorname{Re}_{1}}, \quad S_{2}=i \frac{\beta_{1}^{2}}{\operatorname{Re}_{1}}, \quad \frac{\omega^{\prime}}{\omega_{0}}=\frac{\operatorname{Mo}_{1}^{2}}{\operatorname{Re}_{1}}\left(\frac{4}{3}+\frac{\nu_{0}^{\prime}}{\nu_{0}}\right) \text {, } \\
& \sigma_{1}=\alpha_{1} / \gamma_{1}, \quad \sigma_{2}=\alpha_{1} / \gamma_{2}, \quad \operatorname{Re}_{1}=\frac{\omega r_{1}}{\nu_{0}}, \quad M o_{1}=\frac{\omega r_{1}}{C_{0}} .
\end{aligned}
$$


Again, the expression of $h_{p q}$ for $p=4,5$, and 6 is also omitted here since it is similar to those of $p=1,2$, and 3 ; they can be obtained by replacing $\beta_{1}$ and $\gamma_{1}$ by $\beta_{2}$ and $\gamma_{2}$, and multiplied by -1 [e.g., $h_{43}=$ $\left.\frac{\mathrm{S}_{2} \sigma_{2} \mathrm{n}}{\beta_{2}} \cdot \mathrm{F}_{\mathrm{n}}\left(\beta_{2}\right)\right]$.

Using equations (17) and (19) gives the surface loading expressed in terms of the interface radii and the shell displacement as

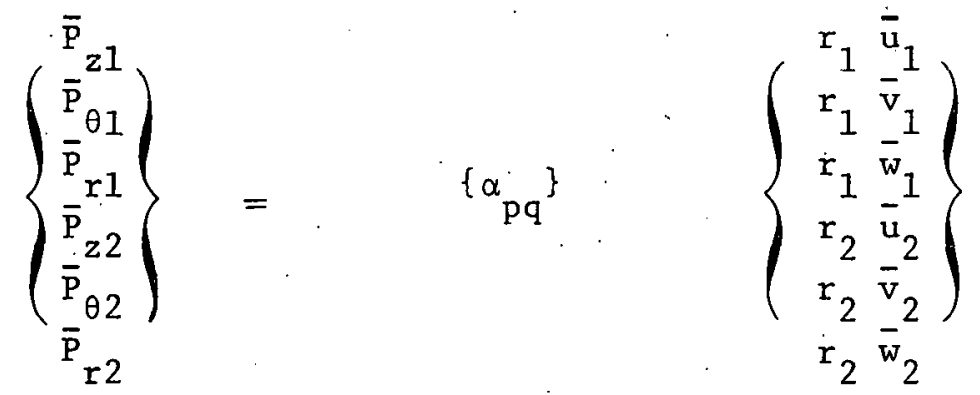

where

$$
\left\{\alpha_{p q}\right\}=\left\{h_{p q}\right\} \quad\left\{a_{p q}\right\}^{-1}
$$

l'he coefficient $\alpha_{p p}$ is proportional to the dynamic fluid stress acting on a shell surface due to its own movement; while the others, $\alpha_{p q}$ for $p \neq q$, are proportional to the dynamic fluid stresses acting on a shell surface in one direction due to the movement in another direction.

The fluid stresses acting on the shells are linear functions of shell motions. In general, the coefficients $\alpha_{p q}$ are complex. The fluid stress can be separated into two components: one proportional to $\operatorname{Re}\left(\alpha_{\mathrm{pq}}\right)$ is in phase with the shell accelerations and is related to the added mass effect, while the other, proportional to $\operatorname{Im}\left(\alpha_{\mathrm{pq}}\right)$, is opposing to the movement of the shells and is related to damping mechanism. If the fluid is inviscid, the second component of the stress opposing shell motion will be zero. 
As shown in equations (17), (19), and (21), the dynamic fluid stress coefficient matrix $\alpha_{\mathrm{pq}}$ is a function of the radius ratio, $r_{2} / r_{1}$, the circumferential wave number, $n$, the axial wave number, $\alpha_{1}$, the Mach number $\mathrm{Mo}_{1}=\frac{\omega \mathrm{r}_{1}}{\mathrm{C}_{\mathrm{o}}}$, the Reynolds number, $\mathrm{Re}_{1}=\frac{\omega \mathrm{r}_{1}^{2}}{v_{0}}$, and the ratio of the fluid viscosities $v_{0}^{\prime} / \nu_{0}:$

It should be noted that the circular frequency $\omega$ and so Mach number $\mathrm{Mo}_{1}$ and Reynolds number $\mathrm{Re}_{1}$ are in general complex numbers. The Mach number $\mathrm{Mo}_{1}$ is considered to include the compressibility effects of the fluid. However, the analysis is valid for a small compressible effect or a small Mach number $\mathrm{Mo}_{1}$ - The Reynolds number $\mathrm{Re}_{1}$ and viscosity ratio $\nu_{0}^{\prime} / \nu_{0}$ are the additional function parameters associated with fluid viscosity. The viscous effect is discussed in detail in the study.

For the case of potential flow where $\nu_{0}=0$, and $\nu_{0}^{\prime}=0$, the Reynolds number $\mathrm{Re}_{1}$ and viscous ratio $v_{0}^{\prime} / v_{0}$ are no longer defined and the coefficient is a function of $r_{2} / r_{1}, n, \alpha_{1}$ and Mo ${ }_{1}$ only. Furthermore, all the elements of the coefficient matrix are zero except the real parts of the four elements: $\operatorname{Re}\left\{\alpha_{33}\right\}, \operatorname{Re}\left\{\alpha_{36}\right\}, \operatorname{Re}\left\{\alpha_{63}\right\}$, and $\operatorname{Re}\left\{\alpha_{66}\right\}$, and no damping is introduced to the system by the ideal fluid [1].

\section{B. Numerical Results}

- The preceding analytical method to evaluate the stress coefficlents is programmed on a digital computer which is listed in the appendix (HDSC) of this report. This program can be used to calculate all elements of the stress coefficient matrix, $\alpha_{p q}$, for two concentric shells separated by viscous fluid for any given set of input parameters $n, r_{2} / r_{1}, \alpha_{1}$, Mo ${ }_{1}$, $\operatorname{Re}_{1}$, and $\nu_{0}^{\prime} / \nu_{0}$ 
As mentioned in Section III.A, the $n$-th order Bessel functions $F_{n}(Z)$ and $G_{n}(Z),\left(Z=\beta_{i}\right.$ or $\left.\gamma_{i}\right)$, in principle, can be either the first and. second kind of Besse1 functions, $J_{n}$ and $Y_{n}$, or the Hankel functions $H_{n}$ ( 1 ) and $\mathrm{H}_{\mathrm{n}}{ }^{(2)} \cdot$. However, in practical applications a proper selection of the functions is required because of the limitations imposed by a digital computer and required accuracy. In gerieral the function $J_{n}$ and $Y_{n}$ can be used for a small argument (e.g., $|\mathrm{Z}| \leq 15)$, while $\mathrm{H}_{\mathrm{n}}$ (1) and $\mathrm{H}_{\ddot{n}}$ (2) are recormended for a large argument. Furthermore, for a very large argument (e.g., $|\mathrm{z}|>50$ ) as in most practical cases, a normalized Besse1 function instead of Bessel function itself is used not only to avoid the overflow interruption but also to maintain the accurate result for the calculated stress coefficient matrix.

Some numerical examples of the stress coefficients were obtained and shown in Table $I$ and Figs. 2 to 5. All examples given are for incompressible fluid ( $\mathrm{Mo}_{1}=0$ ), the length of both shells equal to radius $r_{1}\left(\alpha_{1}=\pi\right)$, and $v_{0}^{\prime}=0$. Also the circular frequency $\omega$ is limited to a purely real number. That is, $\operatorname{Im}(\omega)=\operatorname{Im}\left(\operatorname{Re}_{1}\right)=0$.

Table 1 shows the stress coefficient matrix for $\alpha_{1}=\pi, r_{2} / r_{1}=1.2$ and $\mathrm{Mo}_{1}=0$. Each element is specified by a real part (upper number) and an imaginary part (lower number).

For $n=3$ (Table $1 \mathrm{a}$ ) all the values of $\alpha_{\mathrm{pq}}$ are very small except $\operatorname{Re}\left\{\alpha_{33}\right\}=0.324, \operatorname{Re}\left\{\alpha_{36}\right\}=\operatorname{Re}\left\{\alpha_{63}\right\}=-0.234$, and $\operatorname{Re}\left\{\alpha_{66}\right\}=0.318$. In this case, the Reynolds number is large $\left(\operatorname{Re}_{1}=10^{10}\right)$; as expected the imaginary part of $\alpha_{\mathrm{pq}}$ is not important. The results are consistent with the solutions of the potential flow [1], which shows $\alpha_{33}=0.324$, $\alpha_{36}=\alpha_{63}=-0.234, \alpha_{66}=0.318$ and al1 others are zero. However, for the 
TABLE 1. Dynamic Stress Coeffictent Matrix $\alpha_{\mathrm{pq}}$ for $\alpha_{1}=\pi$, $\mathrm{r}_{2} / \mathrm{r}_{1}=1.2$ and $\mathrm{Mo}_{1}=0.0$.

\begin{tabular}{|c|c|c|c|c|c|c|c|}
\hline 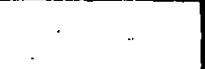 & $\mathrm{p} q$ & 1 & 2 & 3 & 4 & 5 & 6 \\
\hline \multirow{6}{*}{$\operatorname{Re}_{1}=10^{10}$} & 1 & $\begin{array}{r}7.07 \mathrm{E}-6 \\
-7.07 \mathrm{E}-6\end{array}$ & $\begin{array}{l}0 \\
0\end{array}$ & $\begin{array}{r}-7.19 \mathrm{E}-6 \\
7.19 \mathrm{E}-6\end{array}$ & $\begin{array}{l}0 \\
0\end{array}$ & $\begin{array}{l}0 \\
0\end{array}$ & $\begin{array}{r}5.20 \mathrm{E}-6 \\
-5.20 \mathrm{E}-6\end{array}$ \\
\hline & 2 & $\begin{array}{l}0 \\
0\end{array}$ & $\begin{array}{r}7.07 \mathrm{E}-6 \\
-7.07 \mathrm{E}-6\end{array}$ & $\begin{array}{r}-6.86 \mathrm{E}-6 \\
6.86 \mathrm{E}-6\end{array}$ & $\begin{array}{l}0 \\
0\end{array}$ & $\begin{array}{l}0 \\
0\end{array}$ & $\begin{array}{r}4.97 \mathrm{E}-6 \\
-4.97 \mathrm{E}-6\end{array}$ \\
\hline & 3 & $\begin{array}{r}-7.19 \mathrm{E}-6 \\
7.19 \mathrm{E}-6\end{array}$ & $\begin{array}{l}6.86 \mathrm{E}-6 \\
6.86 \mathrm{E}-6\end{array}$ & $\begin{array}{r}3.24 \mathrm{E}-1 \\
-2.15 \mathrm{E}-5\end{array}$ & $\begin{array}{r}-5.20 E-6 \\
5.20 E-6\end{array}$ & $\begin{array}{r}-4.14 \mathrm{E}-6 \\
4.14 \mathrm{E}-6\end{array}$ & $\begin{array}{r}-2.34 \mathrm{E}-1 \\
2.03 \mathrm{E}-5\end{array}$ \\
\hline & 4 & $\begin{array}{l}0 \\
0\end{array}$ & $\begin{array}{l}0 \\
0\end{array}$ & $\begin{array}{r}-5.20 \mathrm{E}-6 \\
5.20 \mathrm{E}-6\end{array}$ & $\begin{array}{r}5.89 E-6 \\
-5.89 E-6\end{array}$ & $\begin{array}{l}0 \\
0\end{array}$ & $\begin{array}{r}7.05 E-6 \\
-7.05 E-6\end{array}$ \\
\hline & 5 & $\begin{array}{l}0 \\
0\end{array}$ & $\begin{array}{l}0 \\
0\end{array}$ & $\begin{array}{r}-4.14 \mathrm{E}-6 \\
4.14 \mathrm{E}-6\end{array}$ & $\begin{array}{l}0 \\
0\end{array}$ & $\begin{array}{r}5.89 E-6 \\
-5.89 E-6\end{array}$ & $\begin{array}{r}5.61 \mathrm{E}-6 \\
-5.61 \mathrm{E}-6\end{array}$ \\
\hline & 6 & $\begin{array}{r}5.20 E-6 \\
-5.20 E-6\end{array}$ & $\begin{array}{r}4.97 \mathrm{E}-6 \\
-4.97 \mathrm{E}-6\end{array}$ & $\begin{array}{r}-2.34 \mathrm{E}-1 \\
2.03 \mathrm{E}-5\end{array}$ & $\begin{array}{r}7.05 E-6 \\
-7.05 E-6\end{array}$ & $\begin{array}{r}5.61 E-6 \\
-5.61 E-6\end{array}$ & $\begin{array}{r}3.18 E-1 \\
-2.11 E-5\end{array}$ \\
\hline \multirow{6}{*}{$\begin{array}{l}\text { (b) } \\
n=3\end{array}$} & 1 & $\begin{array}{r}4.14 \mathrm{E}-2 \\
-1.49 \mathrm{E} 0\end{array}$ & $\begin{array}{l}-1.67 \mathrm{E}-2 \\
-7.32 \mathrm{E}-1\end{array}$ & $\begin{array}{r}-2.13 \mathrm{E}-2 \\
2.32 \mathrm{E} .0\end{array}$ & $\begin{array}{r}7.46 E-3 \\
-3.33 E-1\end{array}$ & $\begin{array}{l}-1.59 E-2 \\
-6.21 E-1\end{array}$ & $\begin{array}{r}1.25 \mathrm{E}-2 \\
-2.60 \mathrm{E} 0\end{array}$ \\
\hline & 2 & $\begin{array}{l}-1.67 \mathrm{E}-2 \\
-7.32 \mathrm{E}-1\end{array}$ & $\begin{array}{r}4.64 \mathrm{E}-2 \\
-1.42 \mathrm{E} \quad 0\end{array}$ & $\begin{array}{r}-2.22 \mathrm{E}-2 \\
.2 .03 \mathrm{E} \quad 0\end{array}$ & $\begin{array}{l}-1.61 \mathrm{E}-2 \\
-6.64 \mathrm{E}-1\end{array}$ & $\begin{array}{r}1.20 \mathrm{E}-2 \\
-1.52 \mathrm{E}-1\end{array}$ & $\begin{array}{r}1.25 \mathrm{E}-2 \\
-2.34 \mathrm{E} 0\end{array}$ \\
\hline & 3 & $\begin{array}{r}-2.13 \mathrm{E}-2 \\
2.32 \mathrm{E} \quad 0\end{array}$ & $\begin{array}{r}-2.22 \mathrm{E}-2 \\
2.03 \mathrm{E} \quad 0\end{array}$ & $\begin{array}{r}3.85 \mathrm{E}-1 \\
-9.38 \mathrm{E} \quad 0\end{array}$ & $\begin{array}{r}-1.28 \mathrm{E}-2 \\
2.47 \mathrm{E} \quad 0\end{array}$ & $\begin{array}{r}-1.02 \mathrm{E}-2 \\
2.06 \mathrm{E} 0\end{array}$ & $\begin{array}{r}-2.91 \mathrm{E}-1 \\
8.93 \mathrm{E} 0\end{array}$ \\
\hline & 4 & $\begin{array}{r}7.46 \mathrm{E}-3 \\
-3.33 \mathrm{E}-1 \\
\end{array}$ & $\begin{array}{l}-1.61 \mathrm{E}-2 \\
-6.64 \mathrm{E}-1\end{array}$ & $\begin{array}{r}-1.28 \mathrm{E}-2 \\
2.47 \mathrm{E} 0\end{array}$ & $\begin{array}{r}3.48 \mathrm{E}-2 \\
-1.20 \mathrm{E} 0 \\
\end{array}$ & $\begin{array}{l}-1.41 \mathrm{E}-2 \\
-6.11 \mathrm{E}-1\end{array}$ & $\begin{array}{r}2.24 \mathrm{E}-2 \\
-2.20 \mathrm{E} 0\end{array}$ \\
\hline & 5 & $\begin{array}{l}-1.59 E-2 \\
-6.21 E-1\end{array}$ & $\begin{array}{r}1.20 \mathrm{E}-2 \\
-1.52 \mathrm{E}-1\end{array}$ & $\begin{array}{r}-1.02 \mathrm{E}-2 \\
2.06 \mathrm{E} \quad 0\end{array}$ & $\begin{array}{l}-1.41 \mathrm{E}-2 \\
-6.11 \mathrm{E}-1\end{array}$ & $\begin{array}{r}3.86 E-2 \\
-9.20 E-1\end{array}$ & $\begin{array}{l}1.66 \mathrm{E}-2 \\
1.89 \mathrm{E} 0\end{array}$ \\
\hline & 6 & $\begin{array}{r}1.25 \mathrm{E}-2 \\
-2.60 \mathrm{E} \quad 0\end{array}$ & $\begin{array}{r}1.25 \mathrm{E}-2 \\
-2.34 \mathrm{E} 0\end{array}$ & $\begin{array}{r}-2.91 \mathrm{E}-1 \\
8.93 \mathrm{E} 0\end{array}$ & $\begin{array}{r}2.24 \mathrm{E}-2 \\
-2.20 \mathrm{E} 0\end{array}$ & $\begin{array}{r}1.66 \mathrm{E}-2 \\
-1.89 \mathrm{E} 0\end{array}$ & $\begin{array}{r}3.78 \mathrm{E}-1 \\
-8.87 \mathrm{E} \mathrm{O}\end{array}$ \\
\hline \multirow{6}{*}{ (c) } & 1 & $\begin{array}{r}2.97 \mathrm{E}-2 \\
-1.95 \mathrm{E} 0\end{array}$ & $\begin{array}{l}-9.55 E-3 \\
-3.96 E-1\end{array}$ & $\begin{array}{r}-3.20 \mathrm{E}-2 \\
3.89 \mathrm{E} 0\end{array}$ & $\begin{array}{l}-3.64 E-3 \\
-7.97 E-1\end{array}$ & $\begin{array}{l}-8.94 E-3 \\
-3.42 E-1\end{array}$ & $\begin{array}{r}2.24 \mathrm{E}-2 \\
-4.19 \mathrm{E} 0\end{array}$ \\
\hline & 2 & $\begin{array}{l}-9.55 E-3 \\
-3.96 E-1\end{array}$ & $\begin{array}{r}6.01 \mathrm{E}-2 \\
-8.44 \mathrm{E}-1\end{array}$ & $\begin{array}{r}-1.11 \mathrm{E}-2 \\
1.14 \mathrm{E} 0\end{array}$ & $\begin{array}{r}-9.01 \mathrm{E}-3 \\
3.65 \mathrm{E}-1\end{array}$ & $\begin{array}{l}2.48 \mathrm{E}-2 \\
3.20 \mathrm{E}-1\end{array}$ & $\begin{array}{r}7.53 \mathrm{E}-3 \\
-1.25 \mathrm{E} \quad 0\end{array}$ \\
\hline & 3 & $\begin{array}{r}-3.20 \mathrm{E}-2 \\
3.89 \mathrm{E} \quad 0\end{array}$ & $\begin{array}{r}-1.11 \mathrm{E}-2 \\
1.14 \mathrm{E} \quad 0 \\
\end{array}$ & $\begin{array}{r}5.82 \mathrm{E}-1 \\
-1.41 \mathrm{E} 1 \\
\end{array}$ & $\begin{array}{r}-2.38 \mathrm{E}-2 \\
3.95 \mathrm{E}-1 \\
\end{array}$ & $\begin{array}{r}-6.23 \mathrm{E}-3 \\
1.10 \mathrm{E} 0 \\
\end{array}$ & $\begin{array}{c}-4.86 \mathrm{E}-1 \\
1.38 \mathrm{E} \cdot 1\end{array}$ \\
\hline & 4 & $\begin{array}{l}-3.64 E-3 \\
-7.97 E-1 \\
\end{array}$ & $\begin{array}{l}-9.01 \mathrm{E}-3 \\
-3.65 \mathrm{E}-1 \\
\end{array}$ & $\begin{array}{r}-2.38 \mathrm{E}-2 \\
3.95 \mathrm{E} \quad 0 \\
\end{array}$ & $\begin{array}{r}2.48 \mathrm{E}-2 \\
-1.62 \mathrm{E} 0 \\
\end{array}$ & $\begin{array}{l}-8.03 E-3 \\
-3.31 E-1 \\
\end{array}$ & $\begin{array}{r}3.28 \mathrm{E}-2 \\
-3.69 \mathrm{E} 0 \\
\end{array}$ \\
\hline & 5 & $\begin{array}{l}-8.94 E-3 \\
-3.42 E-1\end{array}$ & $\begin{array}{l}2.48 E-2 \\
3.20 E-1\end{array}$ & $\begin{array}{r}-6.23 \mathrm{E}-3 \\
1.10 \mathrm{E} \quad 0\end{array}$ & $\begin{array}{l}-8.03 E-3 \\
-3.31 E-1\end{array}$ & $\begin{array}{r}5.01 E-2 \\
-4.67 E-1\end{array}$ & $\begin{array}{r}8.18 \mathrm{E}-3 \\
-1.05 \mathrm{E} 0\end{array}$ \\
\hline & 6 & $\begin{array}{r}2.24 \mathrm{E}-2 \\
-4.19 \mathrm{E} 0\end{array}$ & $\begin{array}{r}7.53 \mathrm{E}-3 \\
-1.25 \mathrm{E} 0 \\
\end{array}$ & $\begin{array}{c}-4.86 \mathrm{E}-1 \\
1.38 \mathrm{E} 1\end{array}$ & $\begin{array}{r}3.28 \mathrm{E}-2 \\
-3.69 \mathrm{E} \quad 0 \\
\end{array}$ & $\begin{array}{r}8.18 \mathrm{E}-3 \\
-1.05 \mathrm{E} 0 \\
\end{array}$ & $\begin{array}{r}5.73 \mathrm{E}-1 \\
-1.38 \mathrm{E} \quad 1 \\
\end{array}$ \\
\hline
\end{tabular}




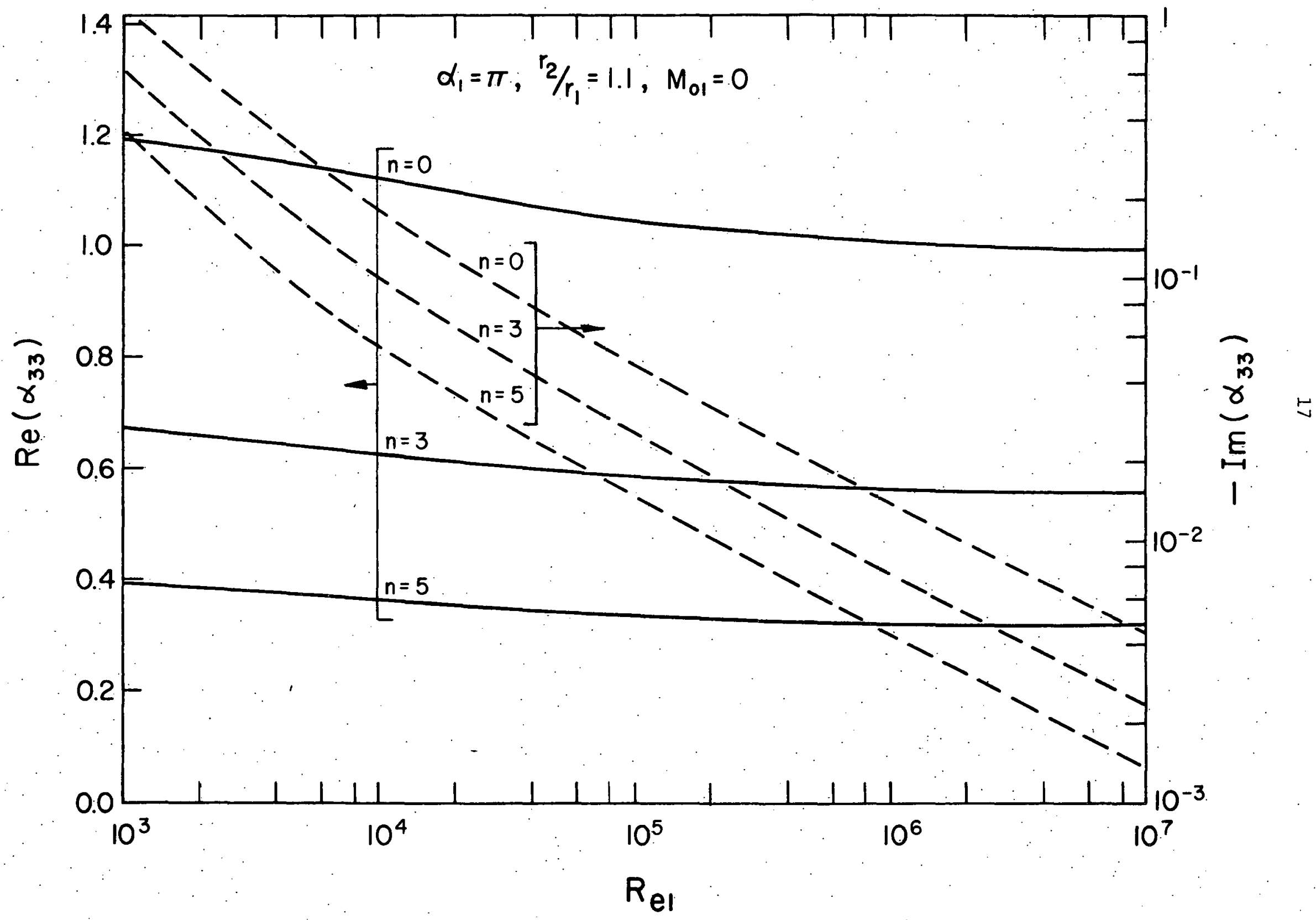

Fig. 2. Stress coefficient $\alpha_{33}$ as a function of Reynolds number $\operatorname{Re} e_{1}$ for $\alpha_{1}=\pi, r_{2} / r_{1}=1.1$, and Mo ${ }_{1}=0.0$. 
case of small Reynolds number, the viscous effect becomes important; the imaginary part of $\alpha_{\mathrm{pq}}$ becomes more important and, in some cases, the imaginary part may be larger than the real part. This can be seen from Table $1 b$ and $1 c$; for $R_{1}=10$, the imaginary parts of $\alpha_{p q}$ are, indeed, much larger than their real parts.

Figure 2 shows the stress coefficient $\alpha_{33}$ as a function of Reynolds number $\operatorname{Re}_{1}=\frac{\omega r_{1}}{\nu_{0}}$ as well as $n$ for $\alpha_{1}=\pi, r_{2} / r_{1}=1.1$ and $M_{1}=0.0$. $\alpha_{33}$ decreases as the Reynolds number $\operatorname{Re}_{1}$ increases; this behavior is the same as that of a vibrating rod in confined viscous fluids [7]. For fixed values of $r_{1}, r_{2}$, and $\nu_{0}, \operatorname{Re}\left\{\alpha_{33}\right\}$ decreases with an increasing $\omega$; this behavior is consistent with the experimental observations [8]. It is interesting to note that the sensitivity of all $\operatorname{Re}\left\{\alpha_{p q}\right\}$ with respect to $\operatorname{Re}_{1}$ is much smaller than $\operatorname{Im}\left\{\alpha_{p q}\right\}$, although both $\operatorname{Re}\left\{\alpha_{p q}\right\}$ and $\operatorname{Im}\left\{\alpha_{\text {pq }}\right\}$ increase with decreasing $\operatorname{Re}_{1}$. Figure 2 also shows that both $\operatorname{Re}\left\{\alpha_{33}\right\}$ and $\operatorname{Im}\left\{-\alpha_{33}\right\}$ are the decreasing function of $n$.

Figures 3 and 4 show the stress coefficients $\alpha_{33}$ and $\alpha_{66}$ as functions of $\mathrm{r}_{2} / \mathrm{r}_{1}, \mathrm{n}$, and $\mathrm{Re}_{1}$ for $\alpha_{1}=\pi$ and $\mathrm{Mo}_{1}=0$. In all cases, as the values of $r_{2} / r_{1}$ increase, $\alpha_{33}$ approaches a constant value while $\alpha_{66}$ monotonically decreases. The different behaviors between $\alpha_{33}$ and $\alpha_{66}$ is attributed to the choice of inner radius $r_{1}$ (rather than $\mathrm{r}_{2}$ ) as a reference length scale. As the value of $\mathrm{r}_{2} / \mathrm{r}_{1}$ becomes large, the movement of either shell is less dependent on the existence of the other and the stress coefficients are expected to approach a constant value if all other parameters for the shell are kept unchanged. However, the present example is set to keep $\alpha_{1}, \mathrm{Re}_{1}$, and $\mathrm{Mo}_{1}$ unchanged, and so $\dot{\alpha}_{2}, \operatorname{Re}_{2}$ and $\mathrm{Mo}_{2}$ which are the important parameters for the outer shell. are increased as $r_{2} / r_{1}$ increases. This means there will be a larger 


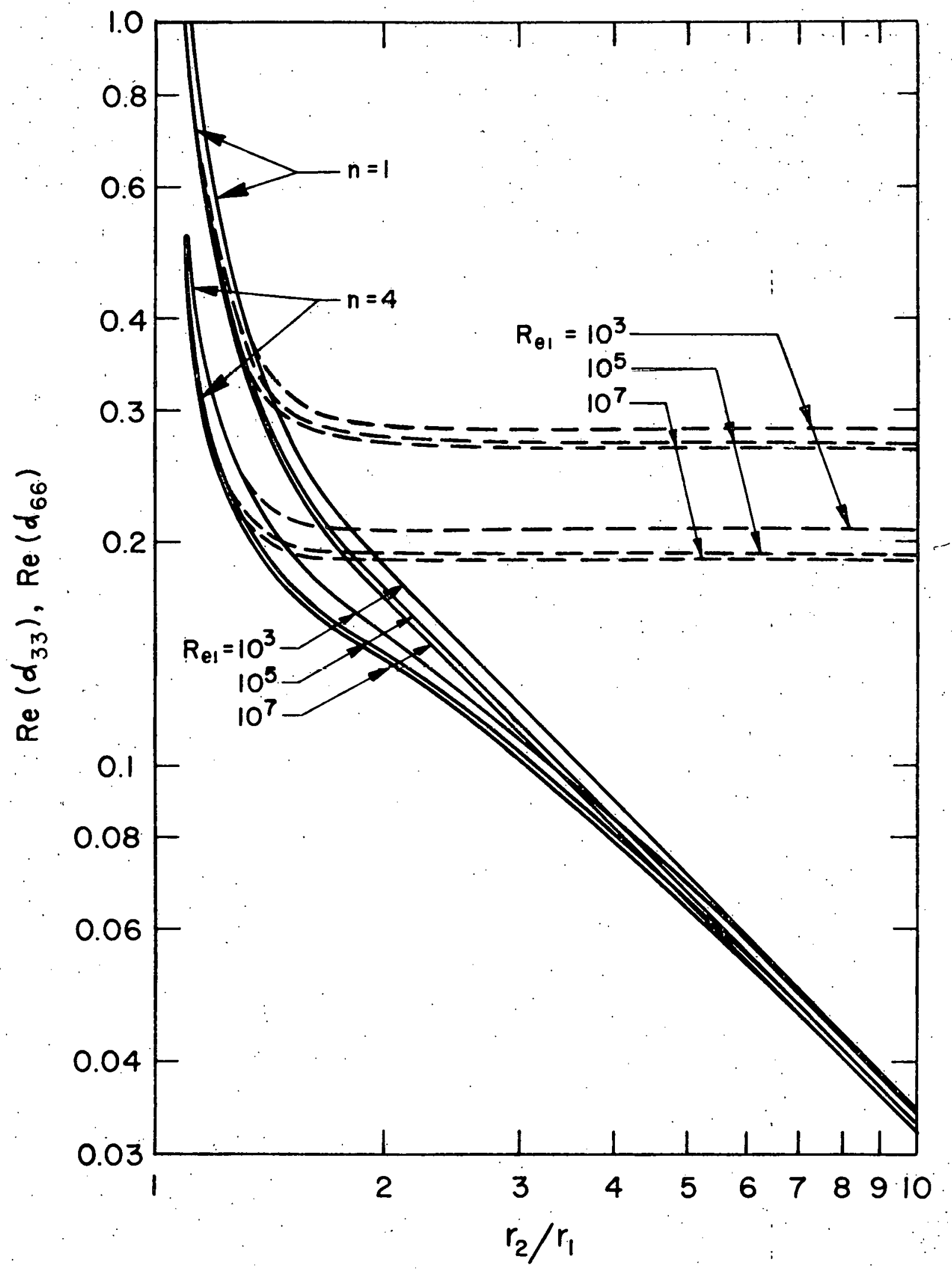

Fig. 3. Real parts of stress coefficients as functions of radius ratio $r_{2} / r_{1}$ for $\alpha_{1}=\pi$ and $\mathrm{Mo}_{1}=0.0 . \quad: \operatorname{Re}\left\{\alpha_{66}\right\} ;-----: \operatorname{Re}\left\{\alpha_{33}\right\}$ 


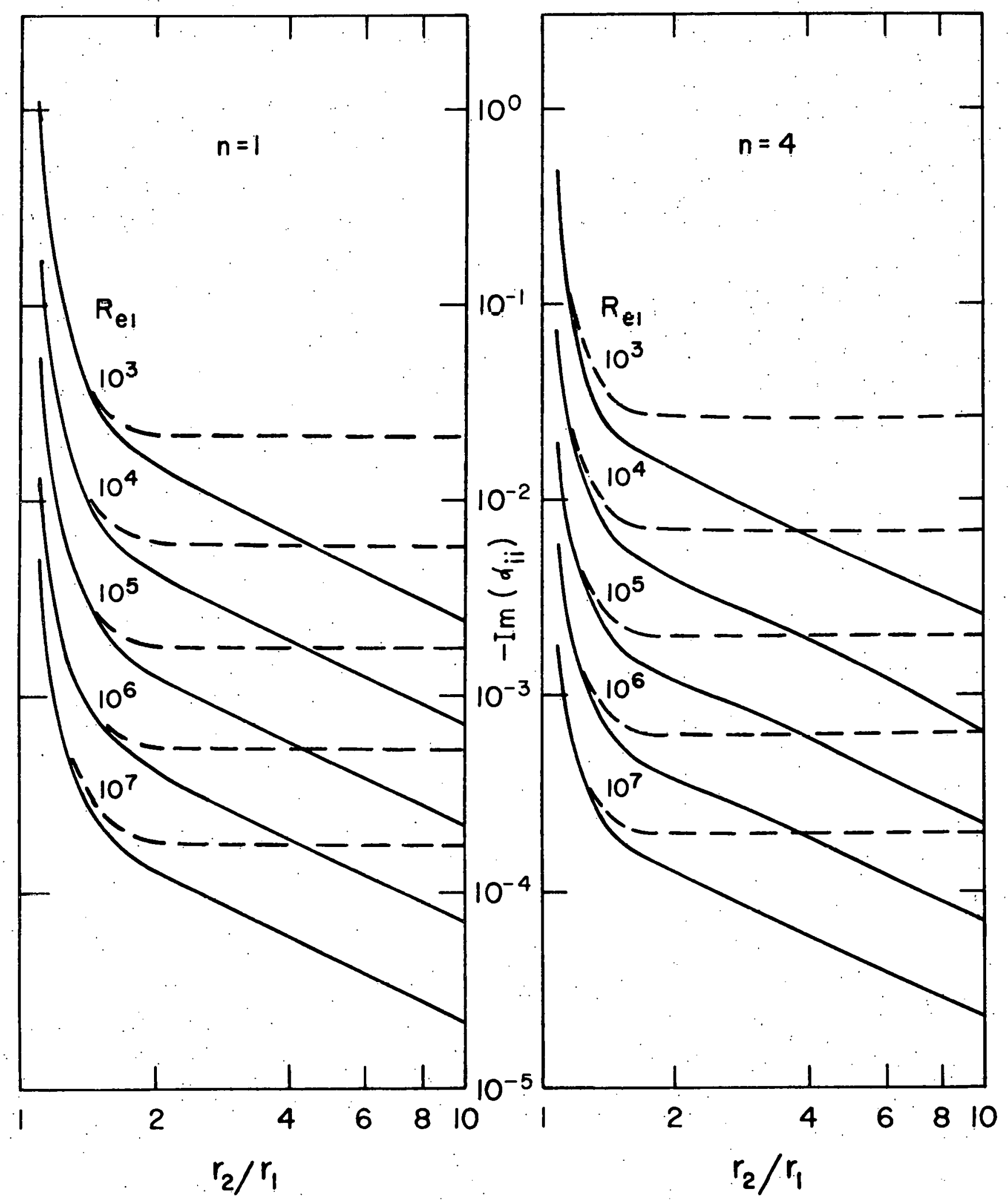

Fig. 4. Imaginary parts of stress coefficients as functions of $r_{2} / r_{1}$ for $\alpha_{1}=\pi$ and $\mathrm{Mo}_{1}=0.0 . \longrightarrow: \operatorname{Im}\left\{-\alpha_{66}\right\} ;-----\operatorname{Im}\left\{-\alpha_{33}\right\}$. 
three-dimensional effect, a larger compressibility effect and a smailer viscous effect for the outer shell as $r_{2} / r_{1}$ increases, although these effects are relatively canstant for the inner shell.

For $r_{2} / r_{1}>2.0$ the outer shell has practically no effects on $\alpha_{33}$ and the effect of the inner shell on the outer shell seems no longer important and the decrease of $\alpha_{66}$ is primarily due to the increase of $\alpha_{2}$ or the decrease of length/radius for the outer she11. With respcct to the dependence of $\mathrm{n}$, both $\alpha_{33}$ and $\alpha_{66}$ are larger for $\mathrm{n}=1$ than those for $n=4$. Also the decreasing rate for $\operatorname{Re}\left\{\alpha_{33}\right\}$ and $\operatorname{Re}\left\{\alpha_{66}\right\}$ is smaller as $\operatorname{Re}_{1}$ increases, while this behavior for $\operatorname{Im}\left\{-\alpha_{33}\right\}$ and $\operatorname{Im}\left[-\alpha_{66}\right]$ is much pronounced.

Figure 5 shows the stress coefficient $\alpha_{36}\left({ }^{\left(=\alpha_{63}\right)}\right.$ as a function of $\mathrm{r}_{2} / \mathrm{r}_{1}, \mathrm{n}$, and $\operatorname{Re}_{1}$ for $\alpha_{1}=\pi$ and $\mathrm{Mo}_{1}=0$. Both $\operatorname{Re}\left\{-\alpha_{36}\right\}$ and $\operatorname{Im}\left\{\alpha_{36}\right\}$ are monotonically decreasing as $\mathrm{r}_{2} / \mathrm{r}_{1}$ increases. It is attributed not only to the increasing separation between two shells, but also to the increasing three-dimensional effect on the outer shell. Note that the example given here is for $\mathrm{Mo}_{1}=0$. For the case of $\mathrm{Mo}_{1}>0$, the value of $\alpha_{p q}$ is expected to be smaller. It can be concluded that the stress coefficient is a decreasing function of the parameters $\alpha_{1}, \mathrm{Mo}_{1}, \mathrm{Re}_{1}$, and $\mathrm{r}_{2} / \mathrm{r}_{1}$ and in most cases it is a decreasing function of $\mathrm{n}$. In some cases $\alpha_{\mathrm{pq}}$ for $\mathrm{p}($ or $q)=2$ : or 4 could be.slightly increased with the increase of $n$. 


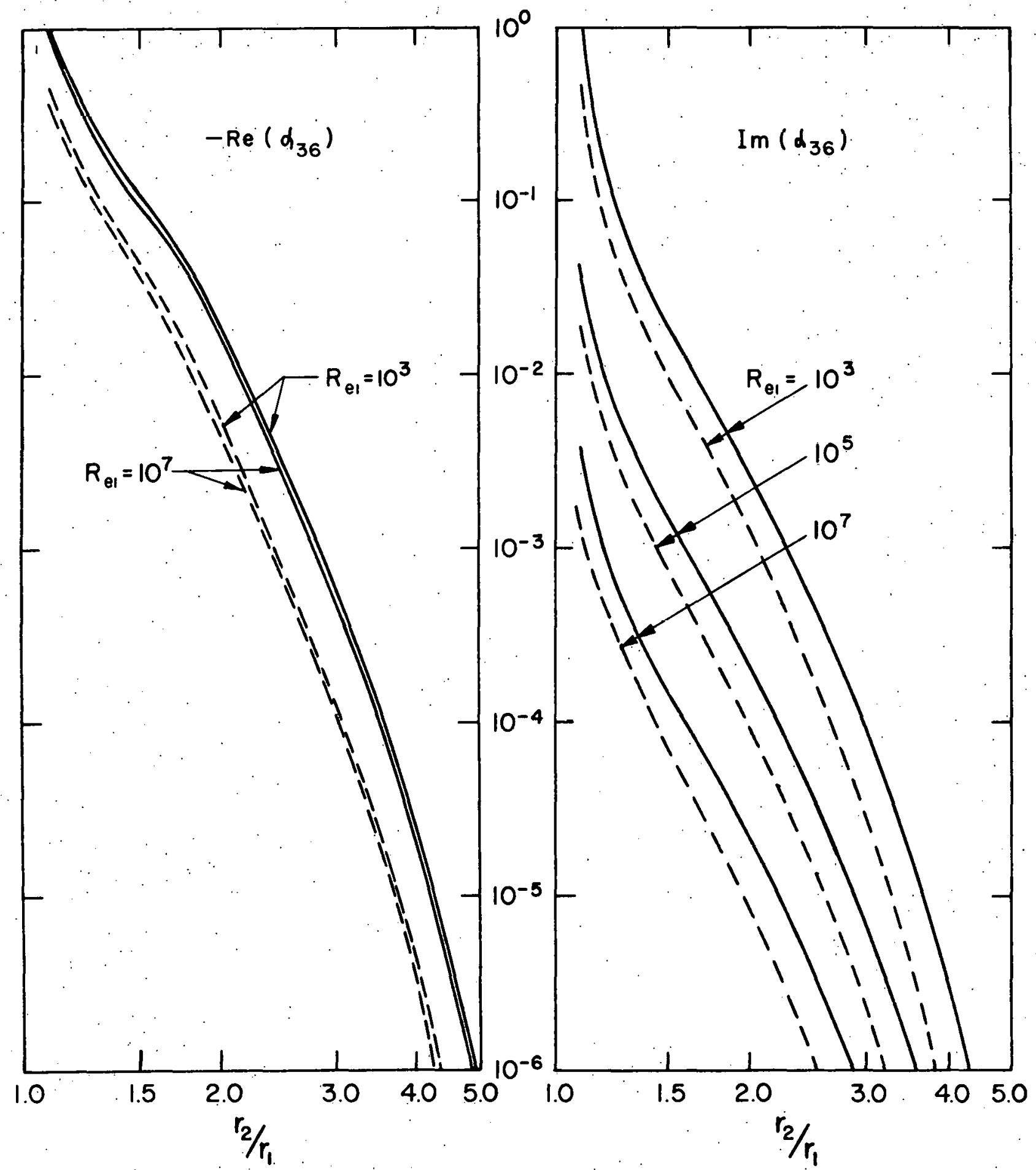

Fig. 5. Stress coefficient $\alpha_{36}$ as a function of $\mathrm{r}_{2} / \mathrm{r}_{1}$ for $\alpha_{1}=\pi$ and $\mathrm{Mo}_{1}=0.0$ 


\section{FREQUENCY EQUATION}

\section{A. Analysis}

Substituting Eqs. (12), (18), and (20) into the shel1 Eq . (1) gives six. linear algebraic homogeneous equations

$$
\left\{b_{p q}\right\}\left\{\begin{array}{c}
\bar{u}_{1} \\
\bar{v}_{1} \\
\bar{w}_{1} \\
\bar{u}_{2} \\
\bar{v}_{2} \\
\bar{w}_{2}
\end{array}\right\}=0
$$

where

$$
\begin{aligned}
& b_{p q}=c_{p q}-\Omega_{1}^{2}\left(\delta_{p q}+\mu_{1} \alpha_{p q}\right) \text {, for } p, q=1,2 \text { and } 3 \text {, } \\
& =-\Omega_{1}^{2}\left(\delta_{p q}+\mu_{1} \frac{r_{2}}{r_{1}} \alpha_{p q}\right), \begin{array}{l}
\text { for } p=1,2, \text { and } 3, \\
\text { and } q=4,5, \text { and } 6,
\end{array} \\
& =-\Omega_{2}^{2}\left(\delta_{p q}+\mu_{2} \frac{r_{1}}{r_{2}} \alpha_{p q}\right), \begin{array}{l}
\text { for } p=4,5, \text { and } 6, \\
\text { and } q=1,2, \text { and } 3,
\end{array} \\
& =\mathrm{C}_{\mathrm{pq}}-\Omega_{2}^{2}\left(\delta_{p q}+\mu_{2} \alpha_{p q}\right), \text { for } p, q=4,5 \text {, and } \dot{6} \text {, } \\
& \Omega_{i}=R_{i} \omega\left[\frac{\rho_{i}\left(1-v_{i}^{2}\right)}{E_{i}}\right]^{1 / 2}, \quad \mu_{i}=\frac{\rho_{0} r_{i}}{\rho_{i} h_{i}}, \\
& \delta_{p q}=1 \text { for } p=q \text {, otherwise } \delta_{p q}=0 \text {, } \\
& C_{11}=\alpha_{1}^{2}+\frac{1-v_{1}}{2} n^{2}\left(1+\frac{\delta_{1}^{2}}{12}\right), \\
& c_{12}=c_{21}=\frac{1+v_{1}}{2} \alpha_{1} n \\
& \mathrm{C}_{22}=\mathrm{n}^{2}+\frac{1}{2}\left(1-v_{1}\right)\left(1+\frac{\delta_{1}^{2}}{4}\right) \alpha_{1}^{2} \text {, }
\end{aligned}
$$




$$
\begin{aligned}
& c_{13}=c_{31}=\alpha_{1} \nu_{1}+\frac{\alpha_{1}^{3}}{12} \delta_{1}^{2}-\frac{\alpha_{1}}{24}\left(1-v_{1}\right) \delta_{1}^{2} n^{2} \\
& c_{23}=c_{32}=n+\frac{\alpha_{1}^{2}}{24}\left(3-v_{1}\right) \delta_{1}^{2} n \\
& c_{33}=1+\frac{1}{12}\left[1-2 n^{2}+\left(\alpha_{1}^{2}+n^{2}\right)^{2}\right] \\
& \delta_{i}=h_{i} / R_{i}
\end{aligned}
$$

The expression of $\mathrm{C}_{\mathrm{pq}}$ for the outer shell can be obtained easily by replacing $\alpha_{1}$ and $\delta_{1}$ by $\alpha_{2}$ and $\delta_{2}$ and changing the subscript for. $C_{\mathrm{pq}}$ from 1,2 , and 3 to 4,5 , and 6 respectively.

The frequency equation of the coupled fluid/shell system is obtained by setting the determinant of the coefficient matrix $b_{p q}$ in equation (22) equal to zero; it can be written as $\left|b_{p q}\right|=0$ or in the function form as

$$
F\left(\alpha_{1}, \gamma_{1}, r_{2} / r_{1}, M o_{1}, \operatorname{Re}_{1}, \nu_{o}^{\prime} / \nu_{0}, n, \Omega_{i}, \delta_{i}, \mu_{i}\right)=0
$$

As pointed out before, the stress coefficient for a given physical condition is not a constant but functions of the frequency parameter, $\omega$, which in general is a complex number. Therefore, in order to determine. the natural frequency and the damping ratio of the coupled system, an iteration procedure is in general required.

It should be noted that, for the case of a viscous fluid, the dynamic fluid stress is not only a function of $n, r_{2} / r_{1}, \alpha_{1}$ and $\mathrm{Mo}_{1}$, but also a function of the vibrational Reynolds number $\mathrm{Re}_{1}:$ This additional parameter $\operatorname{Re}_{1}$ makes the simulation of a scaled model test for a coupled. viscous fluid/ shell system to be very difficult when fluid viscosity effect is important: In a reduced-scale model test, the geometrical simulation commonly employed tends to overestimate the fluid damping and thus the test result will not be conservative. 


\section{B. Numerical Example}

For a specific numerical example, consider the following dimensional values: ${ }^{2} R_{1}=86.52 \mathrm{~cm}(34.0625 \mathrm{in.}), R_{2}=88.74 \mathrm{~cm}(34.9375 \mathrm{in.})$, $h_{1}=0.635 \mathrm{~cm}(0.25$ in. $), h_{2}=1.5875 \mathrm{~cm}\left(0.625\right.$ in.), $E_{1}=E_{2}=1.896 \times 10^{11} \mathrm{~Pa}$ $\left(2.75 \times 10^{7} \mathrm{psi}\right), \nu_{1}=v_{2}=0.27, \rho_{1}=\rho_{2}=7.986 \times 10^{3} \mathrm{~kg} / \mathrm{m}^{3}\left(0.28851 \mathrm{bm} / \mathrm{in} .^{3}\right)$, $\rho_{\mathrm{o}}=9.217 \mathrm{x} \cdot 10^{2} \mathrm{~kg} / \mathrm{m}^{3}\left(0.03331 \mathrm{bm} / \mathrm{in} . .^{3}\right), \nu_{\mathrm{o}}=7.432 \times 10^{-7} \mathrm{~m}^{2} / \mathrm{s}$ $\left(8.0 \times 10^{-6} \mathrm{ft}^{2} / \mathrm{sec}\right), \nu_{0}^{\prime}=0$ and $\mathrm{c}_{0}={ }^{\prime}$. This is the same example as that given in Ref. 1, with the exception that, in the present case, there is no fluid.inside the inner shell and the fluid is viscous in the annulus region. The fluid is considered to be incompressible, $\mathrm{Mo}_{1}=0$, and the shell is assumed to be: simply supported at both: ends.

The frequencies of the system depend on the axial wave number $\alpha_{i}$ and circumferential wave number $n$. The lowest frequency is associated with. the lowest axial wave number, i.e., the wavelength, is equal to twice the shell length which is assumed to be $104.14 \mathrm{~cm}$. (41 in.).

Natural frequencies for the coupled. shell/fluid system can be calculated from Eq. (25): The real and imaginary parts of frequencies, $f_{R}$ and ${ }_{f_{I}}$, are obtained first and then the system natural frequencies. $f_{N}$ and the related modal damping ratio $\zeta$. are given. by $f_{N} \simeq f_{R}$ and.:

$\zeta=\frac{f_{I}}{f_{R}}\left[1+\left(\frac{f^{I}}{f_{R}}\right)^{2}\right]^{-1 / 2}$.

Tables. 2 and 3 and Figs. 6, 7 and 8 summarize the results. The lower natural frequency is associated with the mode in which. two shells move out-of-phase, while the higher frequency is associated with in-phase mode.

Table 2 gives the lowest natural frequencies and the related modal damping ratios of a shell system for several cases: I) inner shell in vacuo; II), outer shell in vacuo; III) an uncoupled shell system with rigid outer shell and $\nu_{0}=\nu_{0}^{\prime}=0 ;$ IV) same as Case III except. $\left.\nu_{0}=7.432 \times 10^{-7} \mathrm{~m}^{2} / \mathrm{s}\left(8.0 \times 10^{-6} \mathrm{ft} / \mathrm{sec}\right) ; \mathrm{V}\right)$ an uncoupled shell" system: 


\begin{tabular}{|c|c|c|c|c|c|c|c|c|c|c|c|c|c|c|}
\hline$n$ & 0 & 1 & 2 & 3 & 4 & 5 & 6 & 7 & 8 & 9 & 10 & 11 & 12 & 13 \\
\hline Case I: & - & - & - & $\begin{array}{c}369 \\
0\end{array}$ & $\begin{array}{c}263 \\
0\end{array}$ & $\begin{array}{c}197 \\
0\end{array}$ & $\begin{array}{c}162 \\
0\end{array}$ & $\begin{array}{c}152 \\
0\end{array}$ & $\begin{array}{c}161 \\
0\end{array}$ & $\begin{array}{c}184 \\
0\end{array}$ & $\begin{array}{c}215 \\
0\end{array}$ & $\begin{array}{c}254 \\
0\end{array}$ & $\begin{array}{c}297 \\
0\end{array}$ & $\begin{array}{c}346 \\
0\end{array}$ \\
\hline Case II & $\dot{-}$ & - & - & $\begin{array}{c}395 \\
0\end{array}$ & $\begin{array}{c}281 \\
0\end{array}$ & $\begin{array}{c}23.8 \\
0\end{array}$ & $\begin{array}{c}241 \\
0\end{array}$ & $\begin{array}{c}278 \\
0\end{array}$ & $\begin{array}{c}338 \\
0\end{array}$ & $\begin{array}{c}412 \\
0\end{array}$ & $\begin{array}{c}498 \\
0\end{array}$ & - & - & - \\
\hline Case III & $\begin{array}{l}66.5 \\
0\end{array}$ & $\begin{array}{c}62.0 \\
0\end{array}$ & $\begin{array}{c}52.5 \\
0\end{array}$ & $\begin{array}{c}43.3 \\
0\end{array}$ & $\begin{array}{c}36.3 \\
0\end{array}$ & $\begin{array}{r}31.7 \\
0\end{array}$ & $\begin{array}{c}29.9 \\
0\end{array}$ & $\begin{array}{c}31.7 \\
0\end{array}$ & $\begin{array}{c}37.5 \\
0\end{array}$ & $\begin{array}{c}47.1 \\
0\end{array}$ & $\begin{array}{c}60.4 \\
0\end{array}$ & $\begin{array}{c}77.1 \\
0\end{array}$ & $\begin{array}{c}98.3 \\
0\end{array}$ & $\begin{array}{c}128.4 \\
0\end{array}$ \\
\hline Case IV & $\begin{array}{l}66.0 \\
.274\end{array}$ & $\begin{array}{l}61.8 \\
.283\end{array}$ & $\begin{array}{l}52.3 \\
.308\end{array}$ & $\begin{array}{l}43.2 \\
.338\end{array}$ & $\begin{array}{l}31.1 \\
.369\end{array}$ & $\begin{array}{l}31.5 \\
.393\end{array}$ & $\begin{array}{l}29.8 \\
.401\end{array}$ & $\begin{array}{l}31.6 \\
.385\end{array}$ & $\begin{array}{l}37.3 \\
.350\end{array}$ & $\begin{array}{l}47.0 \\
.308\end{array}$ & $\begin{array}{l}60.3 \\
.268\end{array}$ & $\begin{array}{l}76.9 \\
.233\end{array}$ & $\begin{array}{l}98.1 \\
.197\end{array}$ & $\begin{array}{l}128.2 \\
.145\end{array}$ \\
\hline Case V & $\begin{array}{c}102.0 \\
0\end{array}$ & $\begin{array}{c}95.2 \\
0\end{array}$ & $\begin{array}{c}81.6 \\
0\end{array}$ & $\begin{array}{c}68.6 \\
0\end{array}$ & $\begin{array}{c}60.0 \\
0\end{array}$ & $\begin{array}{c}59.0 \\
0\end{array}$ & $\begin{array}{c}68.2 \\
0\end{array}$ & $\begin{array}{c}88.3 \\
0\end{array}$ & $\begin{array}{c}119.0 \\
0\end{array}$ & $\begin{array}{r}159 . \\
0\end{array}$ & $\begin{array}{r}208 \\
0\end{array}$ & $\begin{array}{r}267 \\
0\end{array}$ & $\begin{array}{r}340 \\
0\end{array}$ & $\begin{array}{r}445 \\
0\end{array}$ \\
\hline Case VI & $\begin{array}{l}101 \\
.218\end{array}$ & $\begin{array}{r}94.9 \\
.224\end{array}$ & $\begin{array}{l}81.4 \\
.240\end{array}$ & $\begin{array}{l}68.4 \\
.259\end{array}$ & $\begin{array}{l}59.9 \\
.273\end{array}$ & $\begin{array}{r}58.8 \\
.270\end{array}$ & $\begin{array}{l}68.0 \\
.246\end{array}$ & $\begin{array}{r}88.1 \\
.211\end{array}$ & $\begin{array}{r}119.0 \\
.177\end{array}$ & $\begin{array}{l}158 \\
.149\end{array}$ & $\begin{array}{l}208 \\
.126\end{array}$ & $\begin{array}{l}267 \\
.107\end{array}$ & $\begin{array}{l}340 \\
.089\end{array}$ & $\begin{array}{l}445 \\
.062\end{array}$ \\
\hline Case VII & $\begin{array}{c}55.7 \\
0 \\
-- \\
-\end{array}$ & $\begin{array}{c}52.1 \\
0 \\
--- \\
-\end{array}$ & $\begin{array}{c}44.3 \\
0 \\
--- \\
-\end{array}$ & $\begin{array}{c}36.8 \\
0 \\
--- \\
366 \\
0\end{array}$ & $\begin{array}{c}31.2 \\
0 \\
--- \\
269 \\
0\end{array}$ & $\begin{array}{c}28.1 \\
0 \\
--- \\
221 \\
0\end{array}$ & $\begin{array}{c}27.6 \\
0 \\
--- \\
216 \\
0\end{array}$ & $\begin{array}{c}30.0 \\
0 \\
-- \\
243 \\
0\end{array}$ & $\begin{array}{c}36.0 \\
0 \\
--- \\
291 \\
0\end{array}$ & $\begin{array}{c}45.6 \\
0 \\
-- \\
354 \\
0\end{array}$ & $\begin{array}{c}58.6 \\
0 \\
-.- \\
428 \\
0 .\end{array}$ & $\begin{array}{c}74.9 \\
0 \\
-- \\
-\end{array}$ & $\begin{array}{c}95.6 \\
0 \\
-- \\
-\end{array}$ & $\begin{array}{r}125 \\
0 \\
--- \\
-\end{array}$ \\
\hline Case VIII & $\begin{array}{l}55.6 \\
.299 \\
--- \\
-\end{array}$ & $\begin{array}{c}51.9 \\
.309 \\
--- \\
-\end{array}$ & $\begin{array}{c}44.2 \\
.335 \\
--- \\
-\end{array}$ & $\begin{array}{c}36.7 \\
.367 \\
--- \\
366 \\
0\end{array}$ & $\begin{array}{c}31.1 \\
.398 \\
--- \\
269 \\
0\end{array}$ & $\begin{array}{c}28.0 \\
.418 \\
--- \\
221 \\
0\end{array}$ & $\begin{array}{c}27.5 \\
.420 \\
--- \\
216 \\
0\end{array}$ & $\begin{array}{c}29.9 \\
.398 \\
-- \\
243 \\
0\end{array}$ & $\begin{array}{c}35.9 \\
.360 \\
--- \\
291 \\
0\end{array}$ & $\begin{array}{c}45.4 \\
.315 \\
--- \\
354 \\
0\end{array}$ & $\begin{array}{c}58.4 \\
.274 \\
--- \\
428 \\
0\end{array}$ & $\begin{array}{c}74.7 \\
.239 \\
-- \\
-\end{array}$ & $\begin{array}{c}95.4 \\
.202 \\
--- \\
\end{array}$ & $\begin{array}{c}125 \\
.149 \\
--- \\
-\end{array}$ \\
\hline
\end{tabular}

TABLE 2. Natura1 Frequencies (Hz) and Related Modal Damping Ratio (\%) o 
with rigid. inner she11 and $\left.\nu_{0}=\nu_{0}^{\prime}=0 ; V I\right)$ same as Case $V$ except $\nu_{0}=7.432 \times 10^{-7} \mathrm{~m}^{2} / \mathrm{s} ; \mathrm{VII}$ ) a coupled shell system with $\nu_{0}=\nu_{0}^{\prime}=0$; VIII) same as Case VII except $\nu_{0}=7.432 \times 10^{-7} \mathrm{~m}^{2} / \mathrm{s}$. The natural frequencies, $\mathrm{f}_{\mathrm{N}}$, and related modal damping ratio, $\zeta$, (in \%) are given by: the upper and lower numbers in each group.

Table 2 shows that natural frequencies of the system decrease due to the existence of the fluid. Note that: these natural frequencies are practically independent of the variation of fluid viscosity, although the related modal damping ratio is noticeably increased in some cases when the fluid viscosity is included. These results are expected since the fluid viscosity (related. to $\operatorname{Re}{ }_{1}$ ) has a: smaller effect on $\operatorname{Re}\left\{\alpha_{p q}\right\}$ and has a larger effect on $\operatorname{Im}\left\{\alpha_{p q}\right\}$. The decrease in natural frequencies is due to fluid inertia effcct, which is proportional to $\operatorname{Re}\left\{\alpha_{p q}\right\}$, while the increase in damplng is malnly attributed to fluid. drag, which.is proportional to $\operatorname{Im}\left\{\alpha_{p q}\right\}$. For $n \leq 2$ or $n \geq 11$ some of the data are not presented because. of high natural frequencies.

The natural frequencies for the cases of viscous fluid are also shown on Fig. 6. It can be also seen from Table 2 and Fig. 6 that for each circumferential wavenumber $n$ the natural frequencies for the first coupled modes. (out-of-phase modes) are lower than either of the uncoupled natural frequencies, while the frequencies for the second coupled modes. (in-phase modes) are higher than either of the: uncoupled natural frequencies. For $\mathrm{n} \leq 2$ or $\mathrm{n} \geq 11$ the in-phase mode data were not presented because of the high natural frequencies.

Fig.. 7. shows the modal damping ratio $\zeta$ of the shell systems. The effects of fluid viscosity on coupled and uncoupled modes are clearly shown. For the coupled shell systems the effects are mostly pronounced for the out-of-phase modes, but these effects are much smaller. and in fact are 


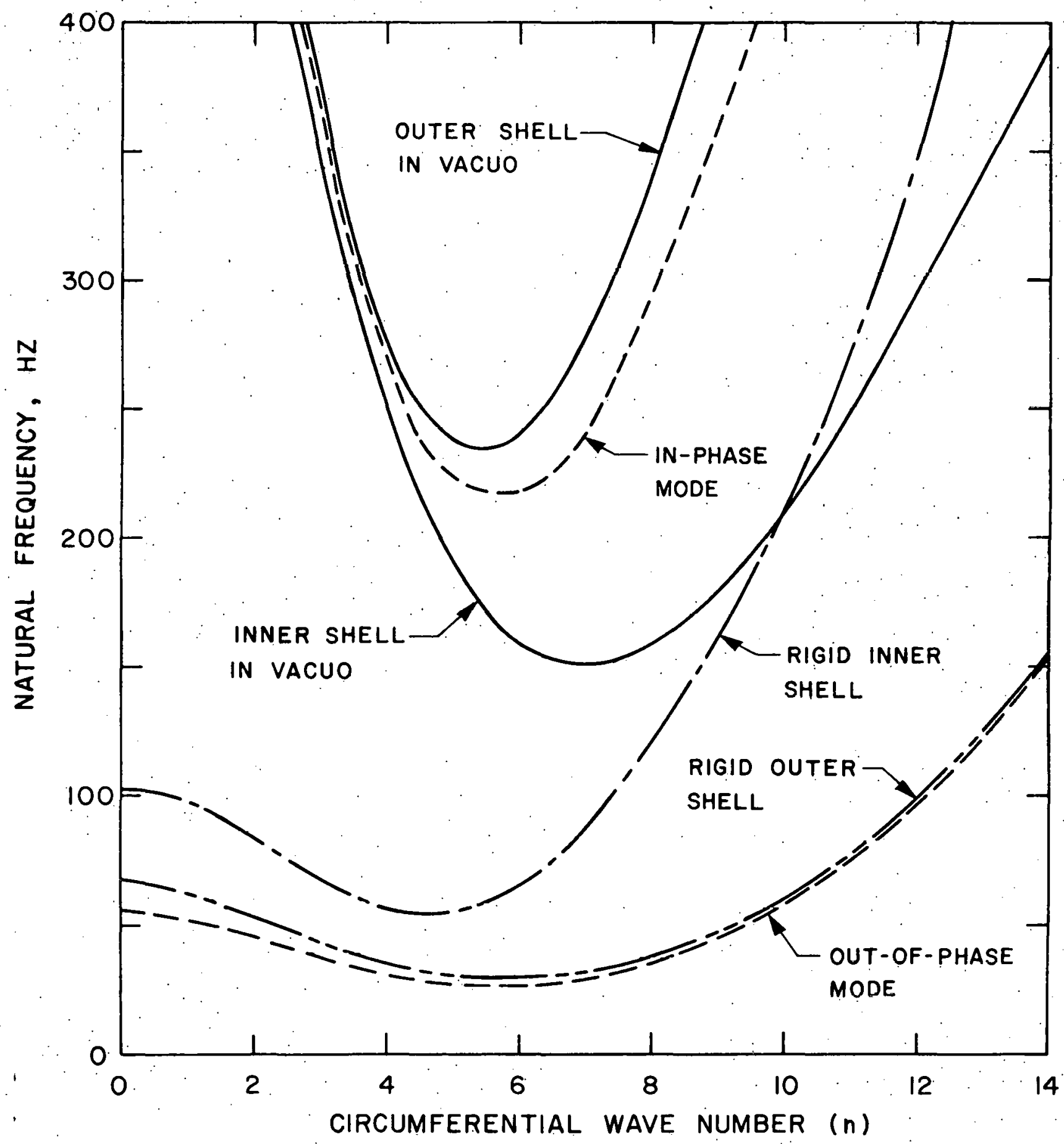

Fig. 6. Natural frequencies of shell systems. 


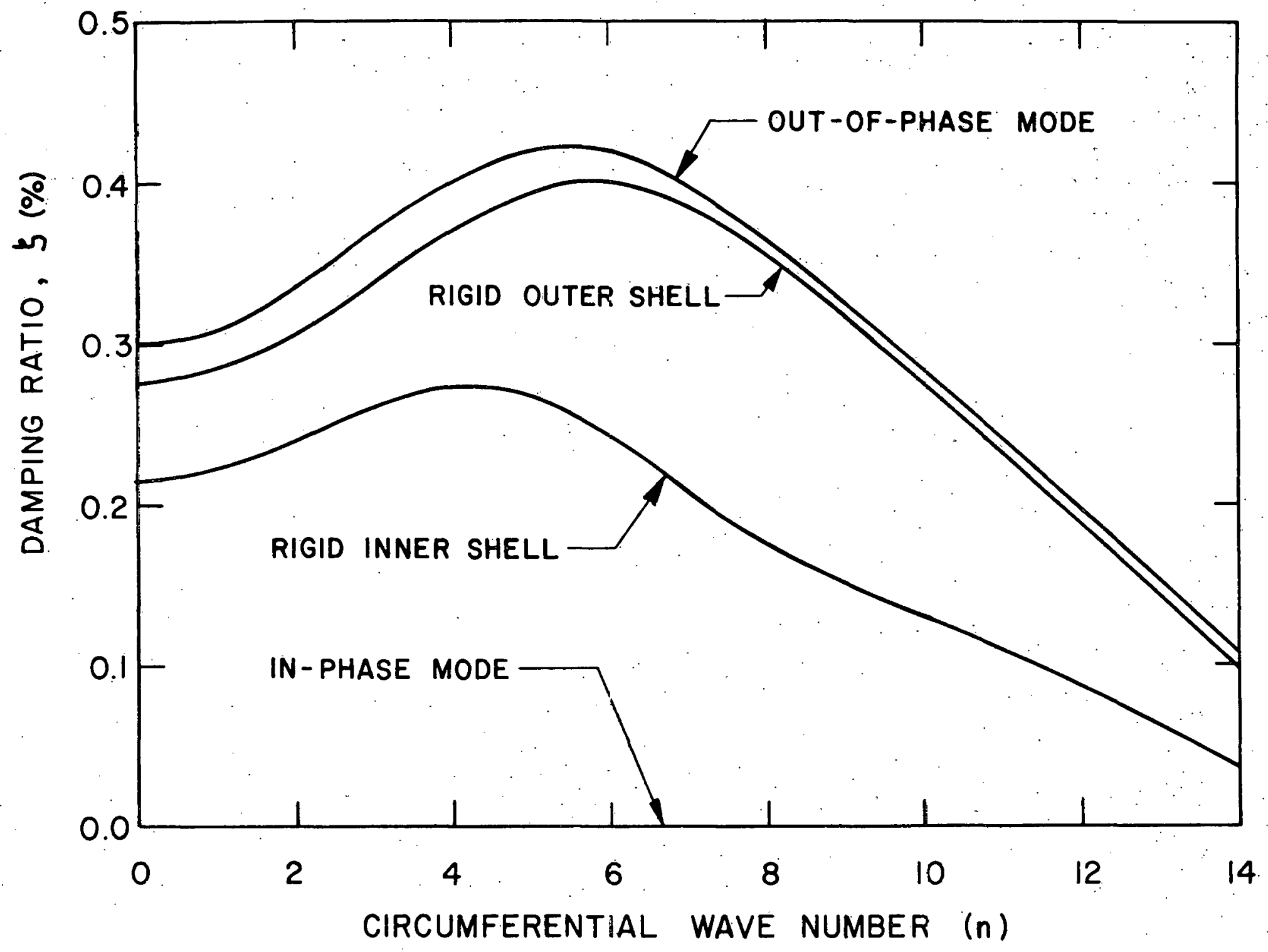


considered to be negligible for the in-phase modes. However, for the uncoupled vibrations, the effects of fluid viscosity remain comparable for. both shells. The reason for large damping ratios on out-of-phase modes and small damping ratios on in-phase. modes can be seen from the differences: of the vibrational mode-shapes which are shown on Table 3 and Fig. 8 . For in-phase modes, both shells as well as the fluid in the annular region are moved almost in the same way (i.e., amplitude ratios $\simeq 1.0$ ) and so the existence of the fluid is hardly noticed by the shells; the frequencies are close to those of outer shell in vacuo. However, for the out-of-phase modes, two shells are moved in opposite directions and the existence of the fluid is mostly detected by the shells. For $n \geq 6$ the movement of inner shell is much larger than that of outer shell and the result is close to that of uncoupled shell system with rigid outer shell.

Additional calculations also have been made to understand the effect of fluid compressibility. It is found that the effect of fluid compressibility, in general, is very small on natural frequency and damping, and in practical applications for structural vibrations, the compressibility of the fluid may be neglected. On the other hand, if the propagation of waves in the system is of interest, fluid compressibility has to be included. 
TABLE 3. Modal Shapes of Out-of-Phase and In-Phase Modes of a Coupled She11 System, Case VIII. $\bar{w}_{1}=1.0$

\begin{tabular}{|c|c|c|c|c|c|c|c|c|c|}
\hline $\mathrm{n}$ & $\mathrm{f}(\mathrm{Hz})$ & $\zeta(\%)$ & $\bar{u}_{1}$ & $\bar{v}_{1}$ & $\overline{\mathrm{u}}_{2}$ & $\bar{v}_{2}$ & $\overline{\mathrm{w}}_{2}$ & $\overline{\mathrm{u}}_{2} / \overline{\mathrm{u}}_{1}$ & $\overrightarrow{\mathrm{v}}_{2} / \overline{\mathrm{v}}_{1}$ \\
\hline 0 & 55.6 & .299 & -.104 & 0 & .042 & 0 & -.419 & -.409 & - \\
\hline 1 & 51.9 & .309 & -.036 & -.27 & .016 & .107 & -.414 & -.433 & -.397 \\
\hline 2 & 44.2 & .335 & .048 & -.333 & -.018 & .131 & -.402 & -.369 & -.392 \\
\hline \multirow{2}{*}{3} & 36.7 & .367 & .075 & -.294 & -.028 & .112 & -.385 & -.373 & -.381 \\
\hline & 366 & 0 & .079 & -.299 & .076 & -.293 & .988 & .959 & .978 \\
\hline \multirow{2}{*}{4} & 31.1 & .398 & .071 & -.242 & -.025 & .084 & -.350 & -.346 & -.348 \\
\hline & 269 & 0 & .072 & -.243 & .071 & -.240 & .990 & .979 & .985 \\
\hline \multirow{2}{*}{5} & 28.0 & .418 & .060 & -.200 & -.016 & .054 & -.272 & -.272 & $\therefore .272$ \\
\hline & 221 & 0 & .060 & -.200 & .060 & -.199 & .995 & .995 & .994 \\
\hline \multirow{2}{*}{6} & 27.5 & .420 & .049 & -.169 & -.009 & .030 & -.178 & -.179 & -.177 \\
\hline & 216 & 0 & .049 & -.169 & .050 & -.170 & 1.01 & 1.01 & 1.01 \\
\hline \multirow{2}{*}{7} & 29.9 & .398 & .040 & -.145 & -.005 & .017 & -.116 & -.117 & -.116 \\
\hline & 243 & 0 & .040 & -.145 & .041 & -.148 & 1.02 & 1.03 & 1.02 \\
\hline \multirow{2}{*}{8} & 35.9 & .360 & .032 & -.127 & -.003 & .011 & -.086 & -.087 & -.086 \\
\hline & 291 & .001 & .033 & -.127 & .034 & -.131 & 1.03 & 1.05 & 1.03 \\
\hline \multirow{2}{*}{9} & 45.4 & .315 & .027 & -.113 & -.002 & .008 & -.074 & -.075 & -.074 \\
\hline & 354 & .001 & .027 & -.113 & .029 & -.118 & 1.05 & 1.06 & 1.05 \\
\hline \multirow{2}{*}{10} & 58.4 & .274 & .022 & -.101 & -.002 & .007 & -.069 & -.070 & -.069 \\
\hline & 428 & .002 & .023 & -.102 & .025 & -.108 & 1.06 & 1:08 & 1.06 \\
\hline 11 & 74.7 & .239 & .019 & -.092 & -.001 & .006 & -.067 & -.068 & -.067 \\
\hline 12 & 95.4 & .202 & .016 & -.084 & -.001 & .005 & -.064 & -.066 & -.064 \\
\hline 13 & 125 & .149 & .014 & -.078 & -.001 & .005 & -.061 & -.062 & -.061 \\
\hline
\end{tabular}




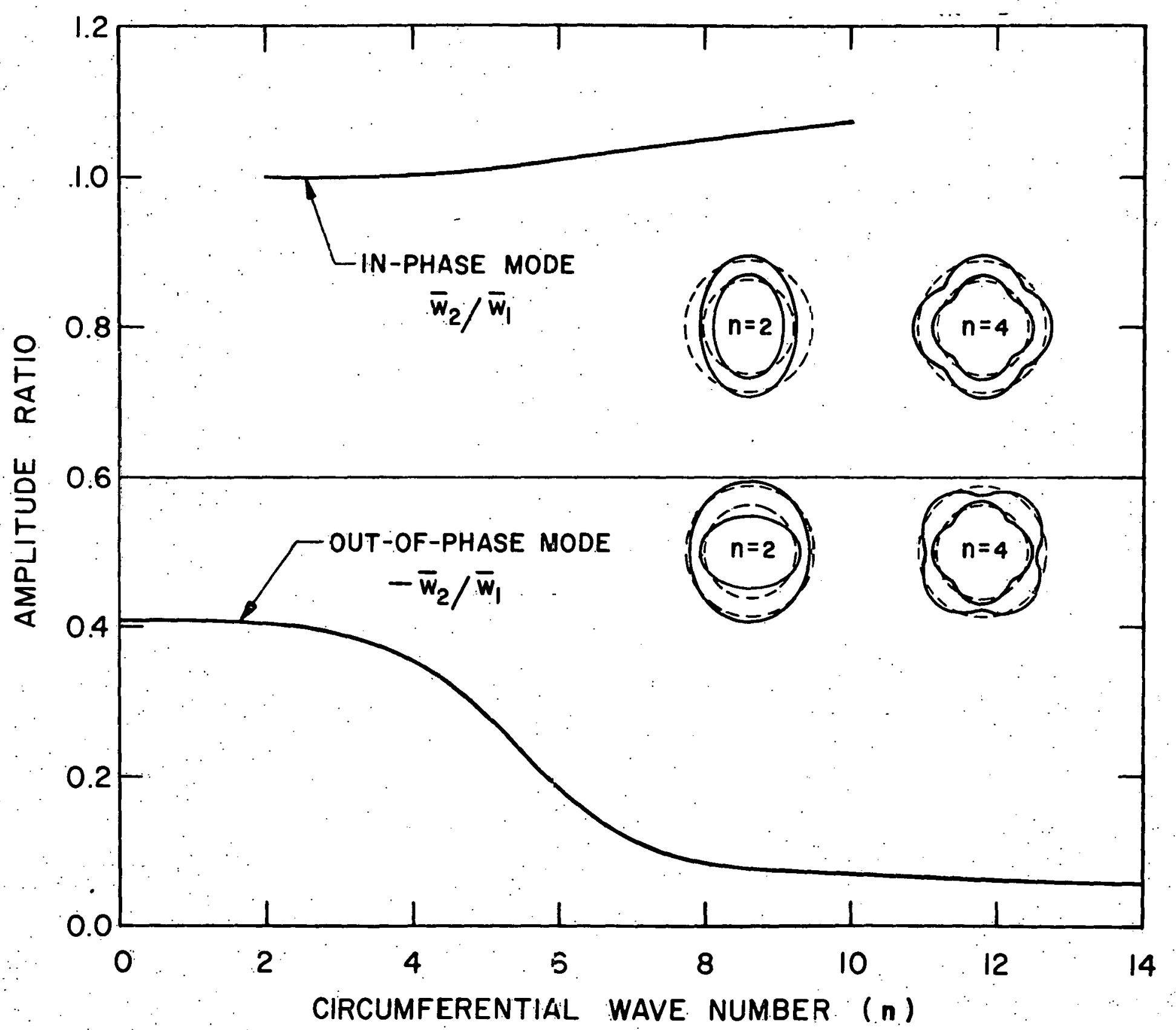

Fig. 8. Modal shape of a coupled fluid/shell system. 


\section{COMPARISON OF ANALYTICAL AND EXPERIMENTAL RESULTS}

An experimental study on a related problem was reported recently by Chung et al. [9]. In the experiment, a steel she1l free at the top edge and soldered to a disc at the bottom was tested. The fluid gap was provided by using a thick concrete shell as the outer cylinder and the fluid is water. A series of tests was made for four different fluid gap sizes: $2.616 \mathrm{~cm}$ $(1.03$ in.), $1.367 \mathrm{~cm}(0.538$ in.), $0.643 \mathrm{~cm}(0.253 \mathrm{in.})$; and $0.384 \mathrm{~cm}(0.151$ in.).

To compare the experimental and analytical results, an analysis was made for the steel shell. The physical properties of the shell and water are as follows: $r_{1}=21.69 \mathrm{~cm}(8.54 \mathrm{in.}), r_{2}=r_{1}+G, h_{1}=0.1473 \mathrm{~cm}$ (0.058 in.); $\mathrm{E}_{1}=1.93 \times 10^{11} \mathrm{~Pa}\left(2.8 \times 10^{7} \mathrm{psi}\right), \nu_{1}=0.3, \rho_{1}=7.47 \times 10^{3} \mathrm{~kg} / \mathrm{m}^{3}$ $\left(0.27 \mathrm{lbm} / \mathrm{in}^{3}\right), \rho_{0}=1.00 \times 10^{3} \mathrm{~kg} / \mathrm{m}^{3} \cdot\left(0.0362 \mathrm{lbm} / \mathrm{in} .^{3}\right), \nu_{0}=1.003 \times 10^{-6} \mathrm{~m}^{2} / \mathrm{s}$ $\left(1.08 \times 10^{-5} \mathrm{ft}^{2} / \mathrm{sec}\right)$ and $\mathrm{L}=51.11 \mathrm{~cm}(20.125 \mathrm{in.})$. In the allalysis, the fluid is considered to be incompressible (i.e., $\mathrm{Mo}_{1}=0$, or $\mathrm{C}_{0}=\infty$ ) and $v_{0}^{\prime}=0$. The numerical result is given only for the lowest axial wavenumber for which the wavelength is assumed to be equal to four times the shell length. Under the stated conditions, one notes at least two important differences between the experiment and the analyses: 1 . In the experiment, the boundary condition of the shell is close to fixed-free end condition, while a.simply-supported end condition is assumed in the analysis; 2 . In the experiment, there exists a relatively large value of structure damping, while in the analysis, the structure damping is assumed to be zero.

In order to make a more meaningful comparison, the normalized frequencies $f_{w} / f_{a}$, where $f_{w}$ and $f_{a}$ are frequencies in water and in air respectively, are given in Table 4 for various water gaps. The experimental data are enclosed by parentheses. Table 4 shows that the analytical and experimental results 
TABLE 4. Comparison of Experimental and Analytical Frequency Ratio

\begin{tabular}{|c|c|c|c|c|c|c|}
\hline \multirow{2}{*}{$\mathrm{n}$} & \multicolumn{2}{|c|}{ Frequencies $\left(\mathrm{f}_{\mathrm{w}} / \mathrm{f}_{\mathrm{a}}\right)$} & \multicolumn{3}{|c|}{ for different water gaps (cm) } & \multirow{2}{*}{$\begin{array}{c}\text { Frequencies } \\
\text { in vacuo } \\
\mathrm{f}_{\mathrm{a}}(\mathrm{Hz})\end{array}$} \\
\hline & $G=0.1917$ & $G=0.3835$ & $G=0.6426$ & $G=1.366$ & $G=2.616$ & \\
\hline 3 & 0.066 & 0.095 & 0.123 & 0.177 & 0.235 & 176 \\
\hline 4 & 0.085 & $\begin{array}{c}0.122 \\
(0.156)\end{array}$ & $\begin{array}{c}0.157 \\
(0.187)\end{array}$ & $\begin{array}{c}0.224 \\
(0.254)\end{array}$ & $\begin{array}{c}0.294 \\
(0.312)\end{array}$ & $\begin{array}{c}151 \\
(160)\end{array}$ \\
\hline 5 & 0.105 & $\begin{array}{c}0.150 \\
(0.180)\end{array}$ & $\begin{array}{c}0.192 \\
(0.234)\end{array}$ & $\begin{array}{c}0.271 \\
(0.331)\end{array}$ & $\begin{array}{c}0.348 \\
(0.414)\end{array}$ & $\begin{array}{c}195 \\
(205)\end{array}$ \\
\hline 6 & 0.125 & $\begin{array}{l}0.177 \\
(0.212)\end{array}$ & $\begin{array}{c}0.227 \\
(0.258)\end{array}$ & $\begin{array}{c}0.315 \\
(0.366)\end{array}$ & $\begin{array}{c}0.397 \\
(0.458)\end{array}$ & $\begin{array}{c}273 \\
(295)\end{array}$ \\
\hline
\end{tabular}


have the similar trend as functions of the gap except the analytical results are smaller.

The frequency ratio $\mathrm{f}_{\mathrm{w}} / \mathrm{f}_{\mathrm{a}}$ is a measure of fluid added mass and is equal to $\left(\frac{m_{s}}{m_{s}+m_{f}}\right)^{1 / 2}$, where $m_{s}$ and $m_{f}$ are shell and added mass per unit shell surface area respectively. Since the added mass depends on shell mode shape, the added mass will be different for cantilevered and simplysupported she1ls. The differences between the theoretical and experimental values aṛe most likely attributed to different boundary conditions.

With respect to the damping, consider the shell vibrating at one of its natural frequencies in water. The equation of motion can be represented by

$$
\left(m_{s}+m_{f}\right) \ddot{x}+\left(c_{s}+c_{f}\right) \dot{x}+\dot{k}_{s} x=0
$$

where $m_{s}, c_{s}$ and $k_{s}$ are mass, structure damping and stiffness corresponding to its particular mode, and $m_{f}$ and $\varepsilon_{f}$ are the added mass and the added damping effects due to a viscous fluld. Both $m_{f}$ and $c_{f}$ are functions of the fluid gap.

Based on Eq. (25), the total damping ratio in water is

$$
\zeta_{t}=\frac{c_{s}+c_{f}}{2 \sqrt{\left(m_{f}+m_{f}\right) k_{s}}}=\sqrt{\frac{m_{s}}{m_{s}+m_{f}} \cdot \zeta_{s}}+\zeta
$$

where $\zeta_{s}=\frac{c_{s}}{2 \sqrt{m_{s} k_{s}}}$ is the structure damping ratio in vacuo and $\zeta=\frac{c_{f}}{2 \sqrt{\left(m_{s}+m_{f}\right) k_{s}}}$ is the damping ratio associated with fluid viscosity.

In the experiment, both $\zeta_{t}$ and $\zeta_{S}$ are measured and $\zeta_{t}$ is increased with the fluid gap. Therefore the viscous damping ratio due to fluid can be calculated from Eq. (26). The analytical and experimental results are given in Fig. 9.. The general behavior of the theoretical fluid damping is similar to the experimental data. Quantitatively, the 


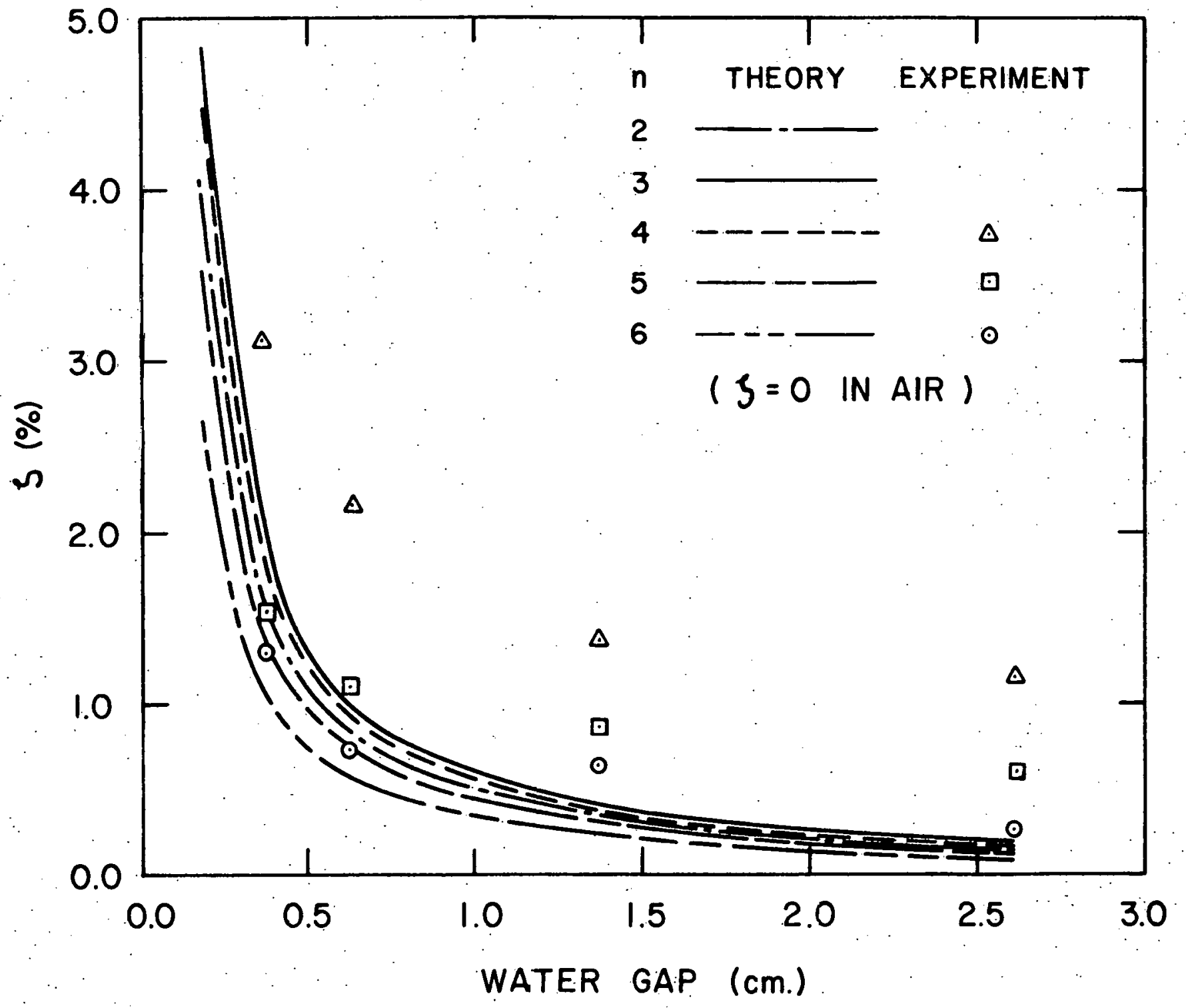

Fig. 9. Comparison of experimental and analytical damping ratio. 
agreement is good for circumferential wave number $\mathrm{n}=5$ and 6 and small gaps, and fair for large gaps. However, the experimental values for $n=4$ are much larger than the analytical results. As pointed out earlier, one of the reasons for the discrepancy is attributed to the boundary conditions. Since the theoretical and experimental models have different boundary conditions, and the added mass $\mathrm{m}_{f}$ and viscous damping $c_{f}$ depend on vibrational mode shape, the two models are not expected to give identical results.

In a similar study for tubes vibrating in a viscous fluid annulus, the analytical results based on the linear viscous theory are in good agreement with the experimental results for damping and added mass [7]. Since the same theory is used here for shells, as long as the motion is small, the analytical results based on the linear viscous theory are expected to be reliable.

Note that both $m_{f}$ and $c_{f}$ decrease with increasing fluid gap. Therefore the term $\sqrt{\frac{m_{s}}{m_{s}+m_{f}}} \zeta$ increases monotonically with fluid gap. On the other hand, the fluid damping, which is a function of $c_{f}$ and $m_{f}$, usually decreases with fluid gap. Since the total damping ratio $\zeta_{t}$ consists of $\sqrt{\frac{m_{s}}{m_{s}+m_{f}}} \zeta_{s}$ and $\zeta$, it is either an increasing function or a decreasing function of the gap depending on the values of structural damping and fluid damping. For the case of a small fluid viscosity and large structural damping, the total damping ratio $\zeta_{t}$ will decrease as the gap decreases. However, eventually as the gap size gets small enough such that fluid damping becomes important, the total damping will increase because of the large increase of the fluid damping. That is, the total damping ratio $\zeta_{t}$ in a dense fluid such as water can be smaller than that in air (or vacuo); the result is quite opposite to what we commonly have expected that damping ratio in water is always larger than that in air. 
VI. CONCLUDING REMARKS

In this report, an analysis is presented for coupled vibrations of two concentric shells separated by a viscous fluid. The coupling effects are accounted for using fluid stress coefficient matrix of concentric shells. With this analysis, natural frequencies and modal damping of coupled concentric shells in viscous fluid can readily be obtained.

In the analysis the three-dimensional, linearized, Navier-Stokes equations governing the motion of viscous fluids are used. The displacements of the shells are assumed to be small such that the equations of state and motion can be linearized. The analytical results are in reasonable agreement with the published experimental data.

Numerical results are presented for a few selected problems for an incompressible fluid. It is shown that the fluid stress coefficient is always a decreasing function of $\alpha_{1}, \mathrm{Mo}_{1}, \mathrm{Re}_{1}$ and $\mathrm{r}_{2} / \mathrm{r}_{1}$ and in most cases it will decrease as $n$ increases. The sensitivity of $\operatorname{Re}{ }_{1}$ on $\operatorname{Re}\left\{\alpha_{p q}\right\}$ is much smaller than that on $\operatorname{Im}\left\{\alpha_{\mathrm{pq}}\right\}$. For generai cases, the magnitude of $\operatorname{Re}\left\{\alpha_{p q}\right\}$ is larger than the magnitude of $\operatorname{Im}\left\{\alpha_{p q}\right\}$; however when $\operatorname{Re}{ }_{1}$ is sufficiently small, the magnitude of $\operatorname{Im}\left\{\alpha_{p q}\right\}$ could be much larger than that of $\operatorname{Re}\left\{\alpha_{p q}\right\}$ and the damping ratio of the system can therefore be very large.

The lowest natural frequency of the coupled shell system with fluid is significantly lower than those of the individual shells. The frequencies for the first coupled modes (out-of-phase modes) are lower than either of the uncoupled natural frequencies. The effect of the fluid viscosity on the system natural frequencies is negligibly small in most practical. systems. However, the modal damping ratio is noticeably increased for some cases when the fluid viscosity is included, especially for the lower 
frequency cases. For a coupled shell the viscous effects are mostly pronounced for the out-of-phase modes; but these effects are considered to be negligible for the in-phase mode. In the preliminary design of practical system components, for $r_{2} / r_{1}>1.15$, the effect of fluid viscosity on damping can be estimated based on the corresponding structure vibrating in an infinite fluid. However, when $r_{2} / r_{1}<1.15$, it is recommended that the viscous damping should be calculated based on the proposed method. Finally, it should be pointed out that results from scaled models, frequently used in practices for design evaluation, may not be conservative if the vibration Reynolds number is not simulated. If the gap is small, or the fluid viscosity is relatively high, the simulation of the vibration. Reynolds number $\mathrm{Re}_{1}$ should be included to ensure that modal damping of the model is properly accounted for. 


\section{ACKNOWLEDGMENTS}

This work was performed under the sponsorship of the Division of Reactor Development and Demonstration, U. S. Energy Research and Development Administration.

The authors wish to express their gratitude to Dr. M. W. Wambsganss for his constructive comments and continued strong support and encouragement. 
REFERENCES

1. Chen, S. S., and Rosenberg, G. S., "Dynamics of a Coupled Shell-Fluid System," Nucl. Eng. and Design, Vol. 32, 1975, pp. 304-310.

2. Krajcinovic, D., "Vibrations of Two Coaxial Cylindrical Shells Containing Fluid," Nucl. Eng. and Design, Vo1. 30, 1974, pp. 242-248.

3. Levin, L., and Milan, D., "Coupled Breathing Vibrations of Two Thin Cylindrical Coaxial She1ls in a Fluid," Proc. Vibration Problems in Industry, Paper No. 616, 1973, Keswirk, F.ngland.

4. Au-Yang, M. K., "Free Vibration of Fluid-Coupled Coaxial Cylindrical Shells of Different Lengths," ASME Paper No. 76-WA/APM-3, 1976.

5. Flügge, W., "Stresses in Shel1s, Springer-Verlag, Berlin (1960).

6. Landan, L. D., and Lifshitz, E. M., Fluid Mechanics, Addison-Wesley Publishing :Co. Inc., Mass. (1959).

7. Chen, S. S., Wambsganes, M. W., and Jendrzejczyk, J. A., "Added Mass and Damping of a Vibrating Rod in Confined Viscous Fluids," Journal of Applied Mechanics, Transactions of the ASME, Vo1. 43, Ser. E, Number 2, June 197.6, pp. 325-329.

8. Miller, R. R., "The Effects of Frequency and Amplitude of Oscillation on the Hydrodynamic Masses of Irregular Shaped Bodies," MS Thesis, University of Rhode Island, 1965.

9. Chung, H., Turula, P., Mulcahy, T. M., and Jendrzejczyk, J. A., "Analysis of a Cylindrical She11 Vibrating in a Cylindrical Fluid Region," ANL-76-48 (1976). 
APPENDIX: COMPUTER PROGRAM (HDSC).

This appendix gives the listing of the computer program, HDSC, which was used to calculate the dynamic fluid stress coefficient matrix, $\alpha_{i j}$, given in this report. This program can be used for a system of two concentric shells separated by a viscous fluid. The program consisting of a series of subroutines with the input parameters $n, r_{2} / r_{1}, \alpha_{1}, \operatorname{Re}\left\{\operatorname{Re}_{1}\right\}, \operatorname{Im}\left\{\operatorname{Re}_{1}\right\}$, $\operatorname{Re}\left\{\mathrm{Mo}_{1}\right\}$ and $\nu_{0}^{\prime} / \nu_{0}$ and the output parameter $\alpha_{i j}$ in a $6 \times 6$ complex matrix is written in Fortran IV for IBM/370 Computer system. 
SUBROUTINE HDSC (NN, R2DR1, ALPR1, RER, REI, SMKR, RNEU, AA)

TO CALCULATE THE FLUID STRESS COEFF. OF TWO CONCENTRIC SHELLS IN VISCOUS FLUID

******* INPUT PARAMETERS ********

NN $=$ CIRCUMFERENTIAL WAVE NUMBER

R2DR $1=R 2 / R 1$, WHERE R 1, R2 ARE THE INTERFACE RADIUS

ALPR1 = AXIAL WAVENUMBER PER R 1

$\mathrm{RER}=\mathrm{R} 1 * 2 * W \mathrm{R} / \mathrm{NEUO}$, REAL PART OF REYNOLDS NUMBEK

REI $=R 1 * 2 * W I / N E U O$, IMAGINARY PART OF REYNOLDS NUMBER

SMKR = R1*WR/CO, REAL PART OF MACH NO.

RNEU = VICOSITY RATIO, NEUOP/NEUO

WHERE $\ldots \ldots$.

WR, WI =REAL AND IMAGINARY PARTS OF CIRCULAR FREQUENCY

NEUO, NEUOP = FLUID VISCOSITY

CO $=$ SPEED OF SOUND IN FLUID

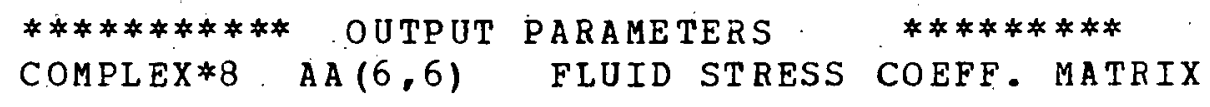

COMMON

C /AAA2/N,AN, ANS, ANM 1, ANP1, TN, TNP2, ANSP 1

C /AAA3/S1,S2,SIG1,SIG2,B1,B2,G1, G2

C/AAA7/ TS1NN1, TS1WP1, EPIB1, EMIB2, EMIDB, TNNM1, IARGZ

C /ABHD/A $(6,6), B(6,6), H(6,6)$, DETERM

C /FLUID/ SMK1PW, RN1PW, RNEUPO

C /WALP/WR,WI,WSR, WSI, ALP 1, ALP2,R21

COMPLEX*16 A,B,H, DETERM

COMPLEX*16 GJ (2), GY (2), BJ (2), BY (2)

COMPLEX*8 S1SG1,S2SG2,TS1,TS2,SG2SM1,TNS1,BNS1,

$\mathrm{C}$ TS2SG2,TSGG,TS2B,GG,BB,TS1SG 1, S2SG2N, DGG, DBB

$\mathrm{C}$ - $E M I G 1, E P I G 2, E P I D G$

COMPLEX $* 8 \quad \mathrm{~S} 1, \mathrm{~S} 2, \mathrm{SIG} 1, \mathrm{SIG} 2, \mathrm{~B} 1, \mathrm{~B} 2, \mathrm{G} 1, \mathrm{G} 2$

COMPLEX * 8 TS1NN1,TS1WP1, EPIB 1, EMIB2, EMIDB

COMPLEX $* 8$ TRC $/(0,01.0) /$, AA $(6,6)$

$S M K 1 P W=S M K R$

RN $1 P$ W $=R E R$

$\mathrm{N}=\mathrm{N} \mathrm{N}$

ALP $1=A L P R 1$

$\mathrm{R} 21=\mathrm{R} 2 \mathrm{DR} 1$

RNEUPO $=$ RNEU

$W R=1.0$

W I $=$ REI/R EP

CALL CONSTO

CALL CONST1.

$\operatorname{SG} 2 \operatorname{SM} 1=\operatorname{SIG} 2 * \operatorname{SIG} 2-1$.

$\mathrm{TNS} 1=\mathrm{TN} * \mathrm{~S} 1$

$\mathrm{S} 2 \mathrm{SG} 2=\mathrm{S} 2 * \mathrm{SIG} 2$

$\mathrm{TS} 1=2 * \mathrm{~S} 1$

$\mathrm{TS} 2=2 * \mathrm{~S} 2$

TS 1SG $1=$ T S $1 *$ SIG 1

TS2 SG $2=$ TS $2 * S I G 2$

$\mathrm{S} 2 \mathrm{SG} 2 \mathrm{~N}=\mathrm{S} 2 \mathrm{SG} 2 * \mathrm{AN}$

I G $2=3$

IF (CABS (G2) . IT. 15.) GO TO 16

IF (ABS (AIMAG (G2)) .GT. 60.) GO TO 40 $I G 2=1$

EPIG $2=C E X P(T R C * G 2)$ 


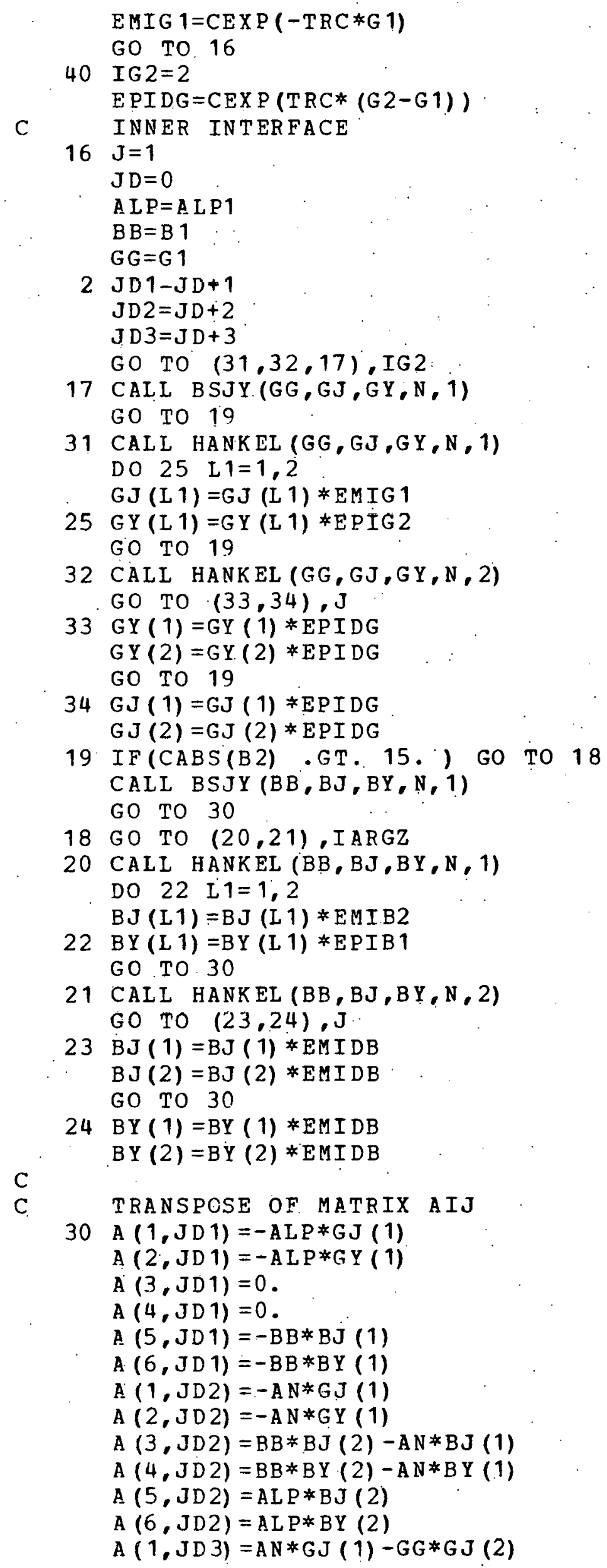

31 CALL HANK EL ( $G G, G J, G Y, N, 1)$ DO $25 \quad \mathrm{~L} 1=1,2$

GJ (L 1) =GJ (L 1) *EMIG 1

$25 \mathrm{GY}(\mathrm{L} 1)=\mathrm{GY}(\mathrm{L} 1) * \mathrm{EPI} \mathrm{I} 2$

GO TO 19

32 CALL HANKEL (GG, GJ, GY, N , 2)

GO TO $(33,34), \mathrm{J}$

$33 \mathrm{GY}(1)=\mathrm{GY}(1) * \mathrm{EPIDG}$

$G Y(2)=G Y(2) * E P I D G$

GO TO 19

$34 \mathrm{GJ}(1)=\mathrm{GJ}(1) \neq \mathrm{EPIDG}$

$\mathrm{GJ}(2)=\mathrm{GJ}(2) * \mathrm{EPIDG}$

19 IF (CABS (B2) .GT. 15.') GO TO 18

CALL BSJY $(B B, B J, B Y, N, 1)$

GO TO 30

18 GO TO $(20,21)$, I ARGZ

20 CALI HANKEL $(B B, B J, B Y, N, 1)$

DO $22 \quad \mathrm{~L} 1=1,2$

$\mathrm{BJ}(\mathrm{L} 1)=\mathrm{BJ}(\mathrm{L} 1) * \mathrm{EMIB} 2$

$22 \mathrm{BY}(\mathrm{L} 1)=\mathrm{BY}(\mathrm{L} 1) * \mathrm{EPIB} 1$

GO TO 30

21 CALL HANKEL ( $B B, B J, B Y, N, 2)$

GO TO $(23,24), \mathrm{J}$

$23 \mathrm{BJ}(1)=\mathrm{BJ}(1) * \mathrm{EMIDB}$

$B J(2)=B J(2) * E M I D B$

GO TO 30

$24 \mathrm{BY}(1)=\mathrm{BY}(1) * \mathrm{EMIDB}$

$B Y(2)=B Y(2) * E M I D B$

C
C

TRANSPCSE OF MATRIX AIJ

$30 A(1, J D 1)=-A L P * G J(1)$

$A(2, J D 1)=-A L P * G Y(1)$

$A(3, J D 1)=0$.

$A(4, J D 1)=0$.

A $(5, J D 1)=-B B * B J(1)$

$A(6, J D 1)=-B B * B Y(1)$

$A(1, J D 2)=-A N * G J(1)$

$A(2, J D 2)=-A N * G Y(1)$

$A(3, J D 2)=B B * B J(2)-A N * B J(1)$

$A(4, J D 2)=B B * B Y(2)-A N * B Y(1)$

$A(5, J D 2)=A L P * B J(2)$

$A(6, J D 2)=A L P * B Y(2)$

$A(1, J D 3)=A N * G J(1)-G G * G J(2)$ 


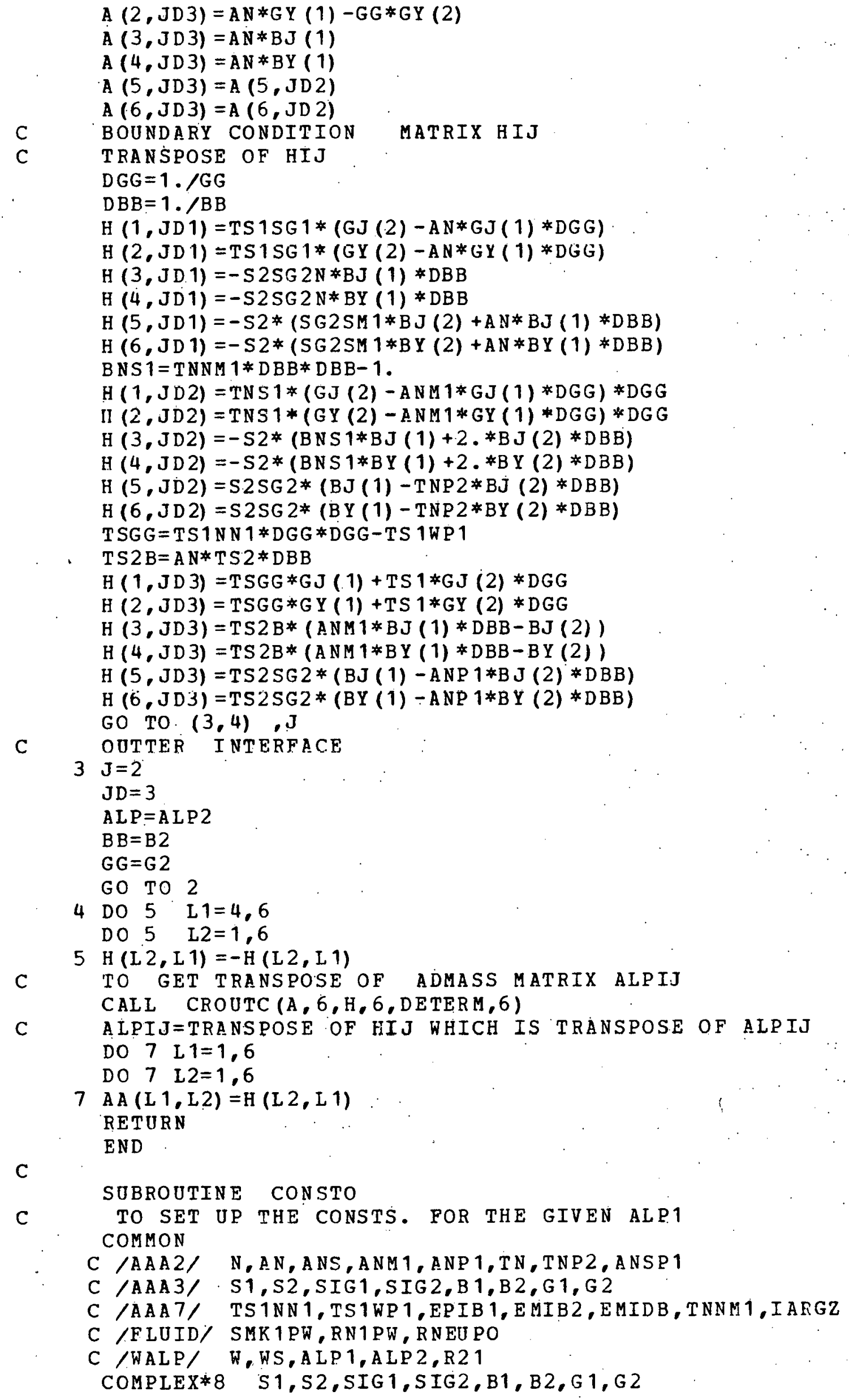


COMPLEX*8

COMPLEX*8

COMPIEX*8

$\mathrm{AN}=\mathrm{N}$

IF (SMK 1PW ITT. 1, E-20) SMK1PW=0.

IF (RN1PW.GT. 1.E30) RN1PW $=1.0 \mathrm{E} 30$

A L P 2 = ALP $1 * R 21$

TO1S $=$ SMK $1 \mathrm{PW} * \mathrm{SMK} 1 \mathrm{PW}$

$\mathrm{TO} 2 \mathrm{~S}=\mathrm{TO} 1 \mathrm{~S} * \mathrm{R} 21 * \mathrm{R} 21$

$\mathrm{RWOI}=(4 . / 3 .+\mathrm{RNEUPO}) * \mathrm{TO} 1 \mathrm{~S} / \mathrm{RN} 1 \mathrm{PW} * \mathrm{TRC}$

$\mathrm{R} 1 \mathrm{SN}=\mathrm{TRC} * \mathrm{RN} 1 \mathrm{PW}$

$\mathrm{R} 2 \mathrm{SN}=\mathrm{R} 1 \mathrm{SN} * \mathrm{R} 21 * \mathrm{R} 21$

A NM $1=\mathrm{AN}-1$.

$A N P 1=A N+1$.

A NS $=A N * A N$

ANSP $1=A N S+1$.

$\mathrm{TN}=2 . * \mathrm{AN}$

TNNM1 $1=$ TN*ANM 1

$T N P 2=T N+2$.

RETURN

ENTRY CONST1

$\mathrm{C}$

TO CALCULATE PARAMETERS FOR A GIVEN FREQUENCY, $W=(W R, W I)$

$\checkmark S=W * W$

A $2 S=A L P 2 * A L P 2$

A $1 S=A L P 1 * A L P 1$

$C C=1 . /(1 .+R$ WOI*W)

$\mathrm{G} 1 \mathrm{~S}=-\mathrm{A} 1 \mathrm{~S}+\mathrm{TO} 1 \mathrm{~S} * \mathrm{C}$ * $\mathrm{WS}$

$\mathrm{G} 1=\mathrm{CSQRT}(\mathrm{G} 1 \mathrm{~S})$

$G 2=C S Q R T(-A 2 S+T O 2 S * C C * W S)$

RNII $=$ R1SN*W

$B 1 S=-A 1 S-R N 1 I$

$\mathrm{B} 1=\mathrm{CSQRT}(\mathrm{B} 1 \mathrm{~S})$

B $2=C S Q R T(-A 2 S-R 2 S N * W)$

SIG $1=A L P 1 / G 1$

$\mathrm{SIG} 2=\mathrm{ALP} 1 / \mathrm{B} 1$

$\mathrm{S} 1=-\mathrm{G} 1 \mathrm{~S} / \mathrm{RN} 1 \mathrm{I}$

$\mathrm{S} 2=1 .+\mathrm{A} 1 \mathrm{~S} / \mathrm{RN} 1 \mathrm{I}$

TS 1 WP $1=2$. *S $1+C C$

TS1NN1 $1=$ TNNM $1 * S 1$

AIB $2=A I M A G(B 2)$

IF (AIB2.. IT. -60.$)$, GO TO 20

IARGZ $=1$

EPIB1 $=C E X P(T R C * B 1)$

$\operatorname{EMIB2}=\mathrm{CEXP}(-\mathrm{TRC} * \mathrm{~B} 2)$

$E M I D B=E M I B 2 * E P I B 1$

RETURN

20. IARGZ $=2$

EPIB $1=1.0$ E70

EMIB $2=0$.

$E M I D B=0$.

$\operatorname{IF}(A \operatorname{IMAG}(B 2-B 1)$. GT. -60.) $\operatorname{EMIDB}=\mathrm{CEXP}(\mathrm{TRC} *(B 1-B 2))$

RETURN

END

C

SUBROUTINE CROUTC (A,N,B, M, DETERM, NMAX)

C

C

$\mathrm{C}$

SOLUTION OF LINEAR EQUATIONS BY THE CROUT METHOD (COMPLEX)

COMPLEX*16 A,B, DETERM,DOTC, V,AMAX,TEMP 


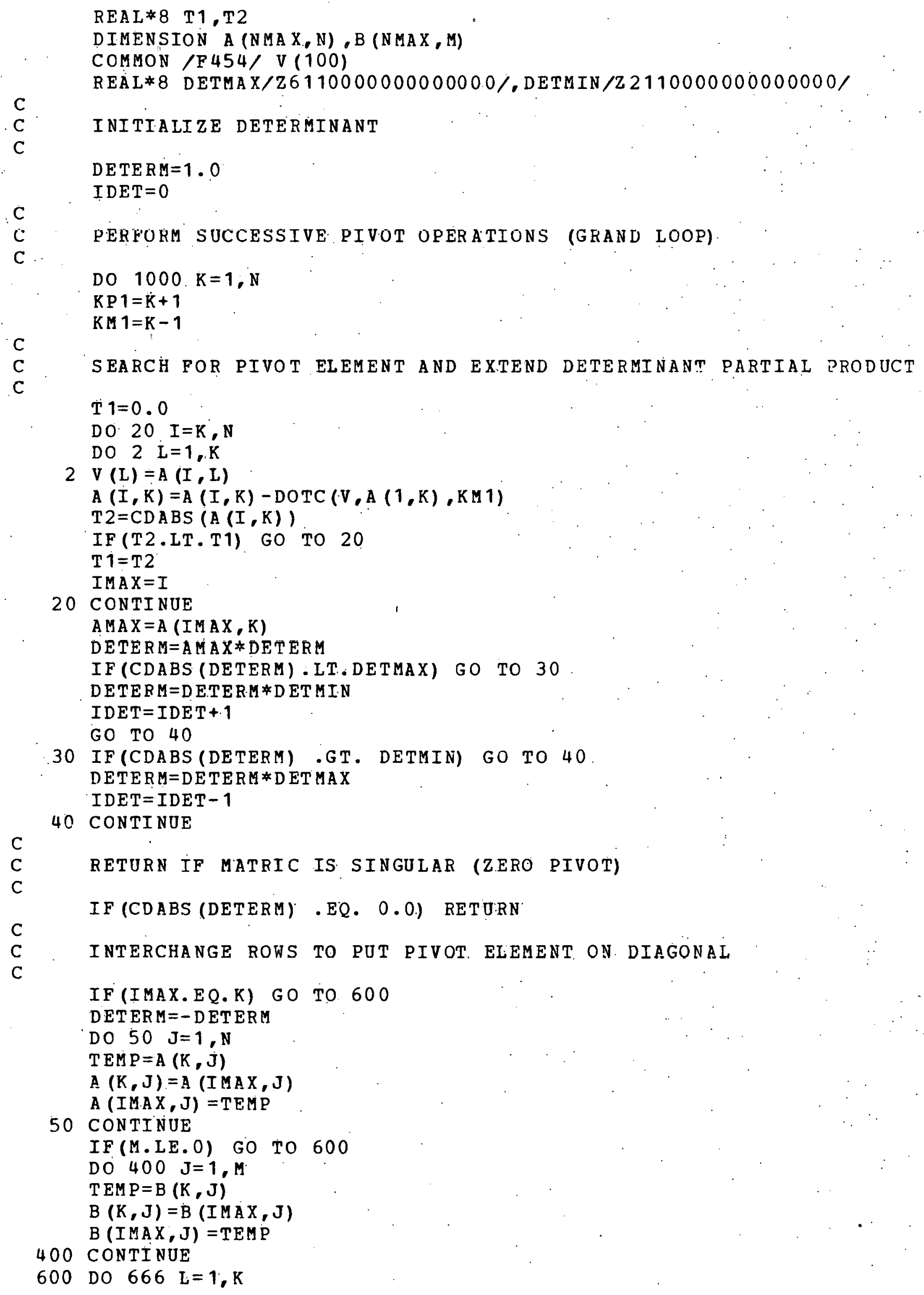




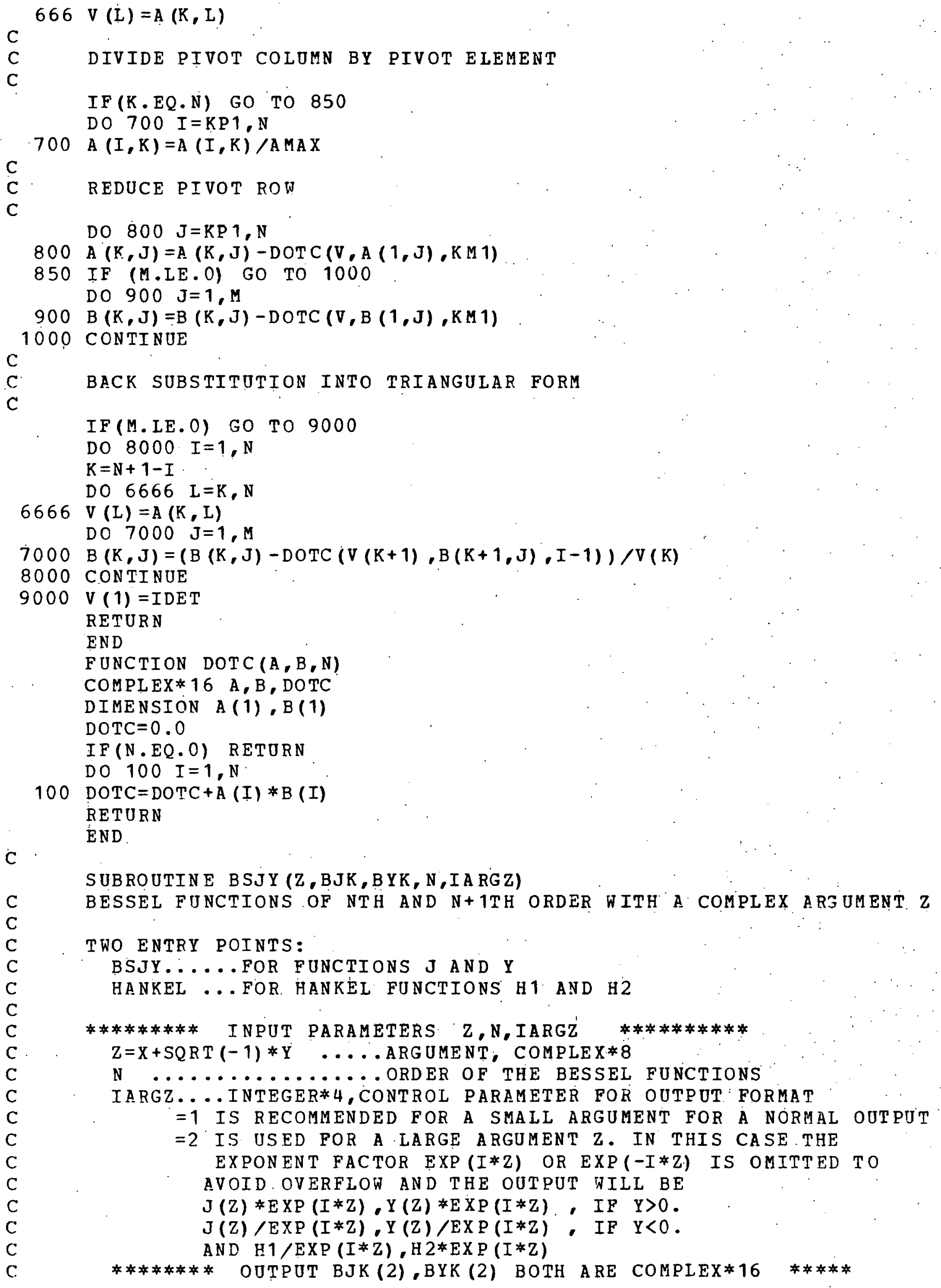


C
C
C
C
C
C
C

J (N) OOR H1(N) STORED AT BJK (1)

$J(N+1)$, OR H1(N+1) STORED AT BJK (2)

$Y(N), O R$ H2 (N) STORED AT BYK (1)

$Y(N+1)$, OR H2 $(\mathrm{N}+1)$ STORED AT BYK(2)

C

$\mathrm{C}$

REF. BESSEL FUNCTIONS WITH SOME PHYSICAL APPIICATIONS BY C.J. TRANTER

REAL*8 CNO, CN 10, CNK, CN 1K, GAMA, TDPI, QNO, QN 10,ZZ1,ZZ2, PI, FNS

C $\quad$ RPI, FNP1S, CHKN (10), CHKN1(10)

COMPLEX $* 16$ JN, JN $1, J N K, H Z, H Z S, H Z N, H Z N 1, H Z N N, H Z N 1 N 1, T J C N, T J C N 1$

C IYNK, TYNK, YN1K, TYN 1K,JN1K, CYO, E1, E2, E 3, QNK, QN1K.

$\mathrm{C}, \mathrm{QN}, \mathrm{QN} 1, \mathrm{PN}, \mathrm{PN} 1, \mathrm{EK} 21 \mathrm{Z}, \mathrm{CSE} 1, \mathrm{CSE} 2, \mathrm{SSE} 1, \mathrm{SSE} 2, \mathrm{EZZ1}, \mathrm{EZZ} 2$

COMPLEX*16 EIZ,HNKEL,TIZ, TIZK,BJK (2),BYK (2)

COMPLEX*8 Z,TRC/ $(0,1.0) /$

DATA PI, GAMA, RPI, TDPI/3.141592.653589793.

C

$0.577215664901533,0.3183098862,0.6366197724 /$

$\mathrm{C}_{\mathrm{T} R T=1}, \mathrm{TNOM} /-1 /$

10 IF (N.IT. O) GO TO 900

IF (N . EQ. INUM) GO TO 100

$\mathrm{C}$

TO INITIALIZE THE NEW CONSTANTS

IF (N.GT. 0 , GO TO 20

$C N O=0$.

NM $1 \mathrm{~F}=0$

$\mathrm{NF}=1$

$\mathrm{NP} 1 \mathrm{~F}=1$

$C N 10=1$.

GO TO 25

$20 \quad N F=1$

$\mathrm{CNO}=1$.

IF (N.IT. 2) GO TO 24

DO $22 K=2, N$

$\mathrm{NF}=\mathrm{NF} * \mathrm{~K}$

$22 \mathrm{CNO}=\mathrm{CNO}+1 \cdot / \mathrm{K}$

$24 \mathrm{~N} / \mathrm{F}=\mathrm{NF} / \mathrm{N}$

$\mathrm{NP} 1 \mathrm{~F}=\mathrm{NF} *(\mathrm{~N}+1)$

$\mathrm{CN} 1 \mathrm{O}=\mathrm{CNO}+1 \cdot /(\mathrm{N}+1)$

$25 \mathrm{NM} 1=\mathrm{N}-1$

$\mathrm{NP} 1=\mathrm{N}+1$

$I N O M=N$

$\mathrm{FNS}=4 . * \mathrm{~N} * \mathrm{~N}$

FNP $1 S=4 . * N P 1 * N P 1$

$\mathrm{QNO}=(\mathrm{FNS}-1) /$.8 .

QN10 $=($ FNP $1 S-1) /$.8 .

$\mathrm{ZZ} 1=\mathrm{PI} / 4 . *(2 * \mathrm{~N}+1)$

$\mathrm{ZZ2}=\mathrm{PI} / 4 \cdot(2 * \mathrm{~N}+3)$

$\mathrm{TRC}=(0 ., 1.0)$

$\operatorname{EZZ1=CDEXP(-TRC*ZZ1)}$

$\operatorname{EZZ} 2=\operatorname{CDEXP}(-\mathrm{TRC} * \mathrm{ZZ2})$

$\mathrm{CHKN}(1)=2 . * \mathrm{QNO}$

CHKN $1(1)=2$. ${ }^{2 N} 10$

DO $101 \mathrm{~K}=2,10$

$\mathrm{FK}=4 . * \mathrm{~K}$

TKM $1 S=(2 * K-1) * 2$

CHKN $(K)=$ CHKN $(K-1) *(F N S-T K M 1 S) / F K$

C

101 CHKN $1(K)=$ CHKN $1(K-1) *($ FNP1S - TKM 1S $) /$ FK

$100 \mathrm{HZ}=\mathrm{Z} * 0.5$ 


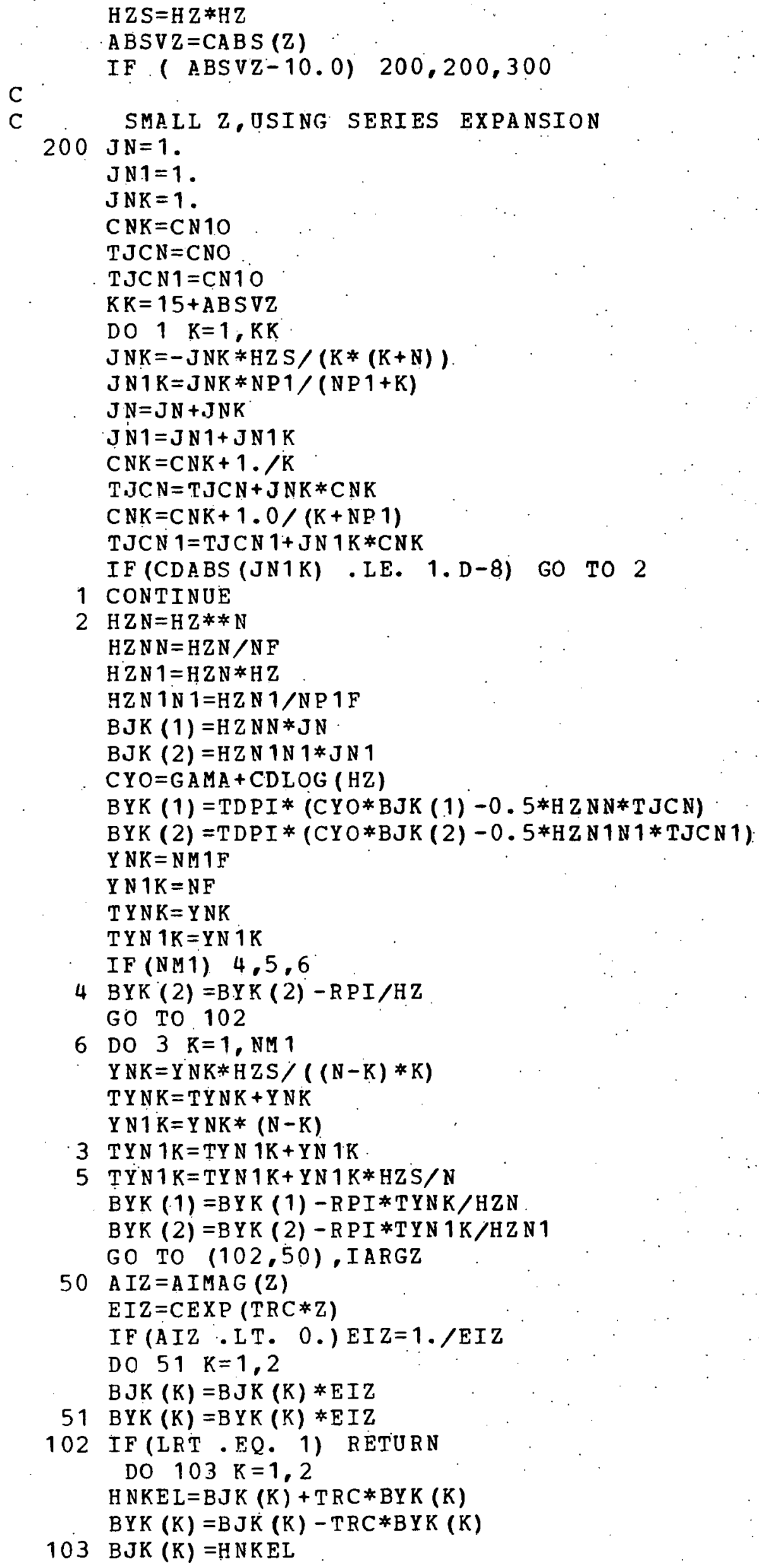


C

RETURN

C

$300 \mathrm{KK}=12 .-\mathrm{ALOG} 10$ ( ABSVZ)
$\mathrm{IF}(\mathrm{KK}$. LE.

GO TO $(104,105)$,LRT

$104 Q N K=Q N O / Z$

$Q N 1 K=Q N 10 / Z$

$Q N=Q N K$

QN $1=Q N 1 K$

$\mathrm{PN}=1$.

PN $1=1$.

DO $30 \mathrm{~K}=2, \mathrm{KK}$

$\mathrm{K} 4=\mathrm{K} * 4$

$K 2=K * 2$

$K 3 S=(K 4-3) * * 2$

$\mathrm{K} 5 \mathrm{~S}=(\mathrm{K} 4-5) * * 2$

$\mathrm{DKZ}=1 . /(256 *(\mathrm{~K} 2-1) *(\mathrm{~K} 2-2) * \mathrm{HZS})$

$Q N K=-Q N K *(F N S-K 3 S) *(F N S-K S S) * D K Z$

$Q N 1 K=-Q N 1 K *(F N P 1 S-K 3 S) *(F N P 1 S-K 5 S) * D K Z$

EK2 1Z $=8$. * $(K 2-1) * Z$

$\mathrm{PN}=\mathrm{PN}+\mathrm{EK} 21 \mathrm{Z} * \mathrm{QNK}$

$\mathrm{PN} 1=\mathrm{PN} 1+\mathrm{EK} 21 \mathrm{Z} * \mathrm{QN} 1 \mathrm{~K}$

$Q N=Q N+Q N K$

$30 Q N 1=Q N 1+Q N 1 K$

GO TO $(31,32)$, IARGZ

31 E 1=Z-ZZ1

E $2=Z-Z Z 2$

$\operatorname{CSE} 1=\operatorname{CDCOS}(\mathrm{E} 1)$

$\operatorname{SSE} 1=\operatorname{CDSIN}(E 1)$

$\operatorname{CSE} 2=\operatorname{CDCOS}(E 2)$

SSE $2=\operatorname{CDSIN}(E 2)$

GO TO 33

32 AIZ = AMAG (Z)

CSE $1=0.5 * E Z Z 1$

SSE $1=0.5 * E Z Z 1 / T R C$

$\operatorname{CSE} 2=0.5 * \operatorname{EZZ} 2$

SSE $2=0.5 * E Z Z 2 / \mathrm{T} \mathrm{RC}$

IF (AIZ . LT. -10. ) GO TO 33

IF (AIZ .LT. 10.) GO TO 35

SSE $1=-S S E 1$

S SE $2=-\operatorname{SSE} 2$

$33 \mathrm{E} 3=1 \cdot / \mathrm{CDSQRT}(\mathrm{PI} * \mathrm{HZ})$

$\operatorname{BJK}(1)=\mathrm{E} 3 *(\mathrm{PN} * \mathrm{CSE} 1-\mathrm{QN} * \mathrm{SSE} 1)$

$B Y K(1)=E 3 *(P . N * S S E 1+Q N * C S E 1)$

$\operatorname{BJK}(2)=E 3 *(P N 1 * C S E 2-Q N 1 * S S E 2)$

$B Y K(2)=E 3 *(P N 1 * \operatorname{SSE} 2+Q N 1 * C S E 2)$

RETURN

35 EIZ $=$ CEXP $(T R C * Z)$

IF (AIZ . LT. 0.) EIZ=1./EIZ

$\mathrm{E} 1=\mathrm{Z}-\mathrm{ZZ} 1$

$\mathrm{E} 2=\mathrm{Z}-\mathrm{ZZ2}$

$\operatorname{CSE} 1=E I Z * \operatorname{CDCOS}(E 1)$

$\operatorname{SSE} 1=\operatorname{EIZ} * \operatorname{CDSIN}(\mathrm{E} 1)$

$\operatorname{CSE} 2=E I Z * \operatorname{CDCOS}(E 2)$

$\operatorname{SSE} 2=\mathrm{EIZ} * \operatorname{CDSIN}(\mathrm{E} 2)$

GO TO 33

ENTRY HANKEL (Z, BJK,B.YK, N, I ARGZ)

$\mathrm{L} R \mathrm{~T}=2$ 


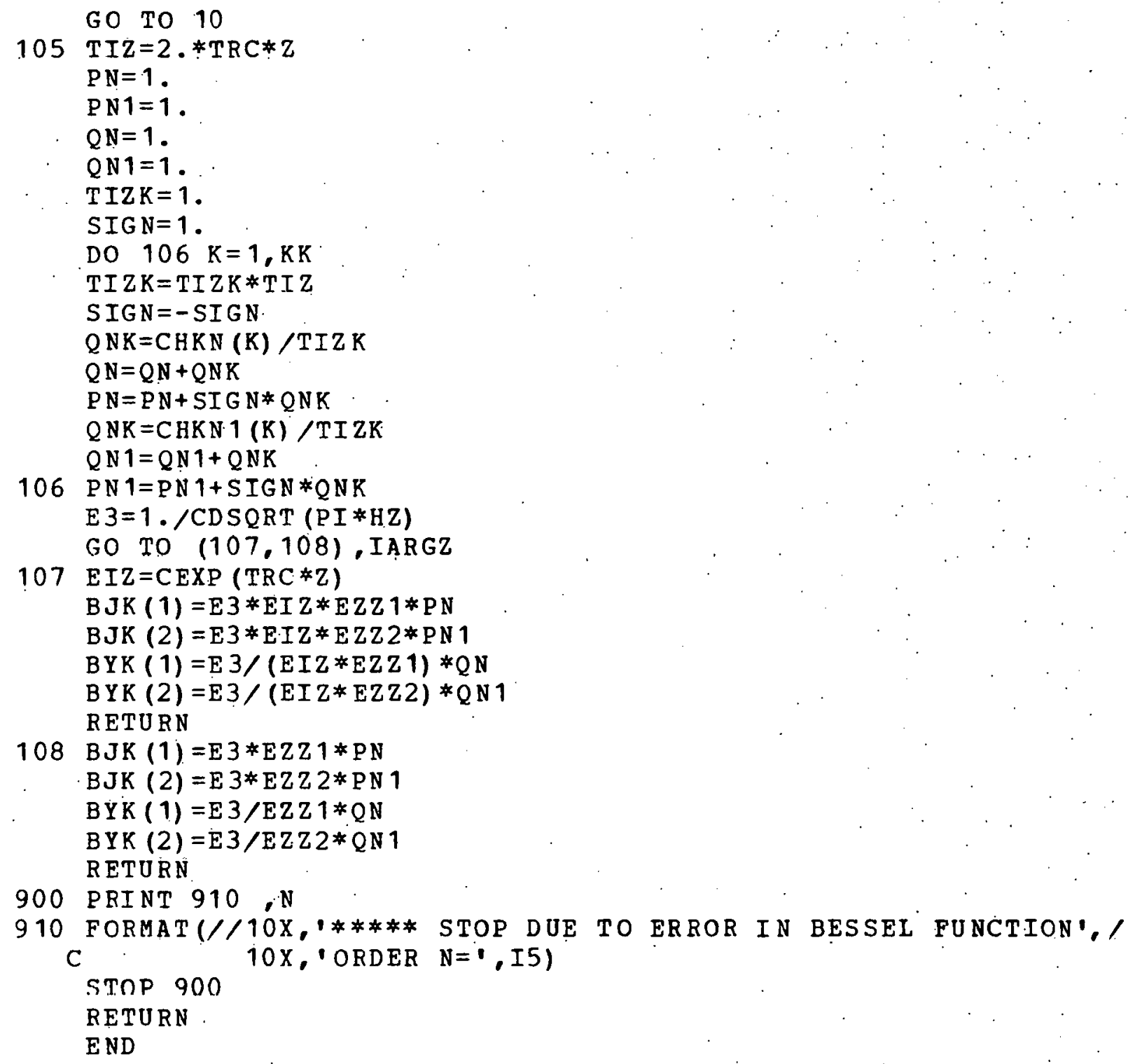

